\title{
MALE MATE CHOICE IN THE TRINIDADIAN GUPPY (POECILIA RETICULATA) UNDER VARYING SPERM COMPETITION AND FEMALE QUALITY
}

\section{by}

\section{Sarah B. Jeswiet}

\author{
A thesis submitted to \\ The Faculty of Graduate and Postdoctoral Affairs \\ in partial fulfillment of the requirements for the degree of
}

Master of Science

in

Biology
Department of Biology
Carleton University
Ottawa, Canada

10 September 2010

(C) Sarah B. Jeswiet, 2010 
Library and Archives

Canada

Published Heritage Branch

395 Wellington Street Ottawa ON K1A 0N4

Canada
Bibliothèque et

Archives Canada

Direction du

Patrimoine de l'édition

395, rue Wellington

Ottawa ON K1A ON4

Canada
Your file Votre référence

ISBN: 978-0-494-71584-0

Our file Notre référence

ISBN: 978-0-494-71584-0
NOTICE:

The author has granted a nonexclusive license allowing Library and Archives Canada to reproduce, publish, archive, preserve, conserve, communicate to the public by telecommunication or on the Internet, loan, distribute and sell theses worldwide, for commercial or noncommercial purposes, in microform, paper, electronic and/or any other formats.

The author retains copyright ownership and moral rights in this thesis. Neither the thesis nor substantial extracts from it may be printed or otherwise reproduced without the author's permission.
AVIS:

L'auteur a accordé une licence non exclusive permettant à la Bibliothèque et Archives Canada de reproduire, publier, archiver, sauvegarder, conserver, transmettre au public par télécommunication ou par l'Internet, prêter, distribuer et vendre des thèses partout dans le monde, à des fins commerciales ou autres, sur support microforme, papier, électronique et/ou autres formats.

L'auteur conserve la propriété du droit d'auteur et des droits moraux qui protège cette thèse. Ni la thèse ni des extraits substantiels de celle-ci ne doivent être imprimés ou autrement reproduits sans son autorisation.
In compliance with the Canadian Privacy Act some supporting forms may have been removed from this thesis.

While these forms may be included in the document page count, their removal does not represent any loss of content from the thesis.
Conformément à la loi canadienne sur la protection de la vie privée, quelques formulaires secondaires ont été enlevés de cette thèse.

Bien que ces formulaires aient inclus dans la pagination, il n'y aura aucun contenu manquant. 


\begin{abstract}
Theory predicts that male mate choice should evolve when males experience a cost to mating and females vary in quality. Here, I used the Trinidadian guppy as a model study species to validate a method (the dichotomous-choice test) for quantifying mate preference and to investigate male mating preferences in response to socio-sexual cues as predictors of sperm competition and visual cues as predictors of female fecundity. Male association times with females, quantified in a dichotomous-choice test, were significantly positively correlated with sexual behaviours directed at paired females. When all else was equal, males tended to avoid associating with females they perceived as being associated with a higher risk of sperm competition, and the presence of a rival male nearby was sufficient to influence a male's mating preference. Male mating behaviour was not sensitive to the intensity of sperm competition and male preference for larger females outweighed cues predicting sperm competition.
\end{abstract}




\section{ACKNOWLEDGEMENTS}

I would like to thank my advisor, Dr. Jean-Guy Godin, for his guidance and support throughout my Master's program, and for giving me the opportunity to conduct field research in Trinidad and Costa Rica. I also extend my gratitude to the members of my Advisory Committee, Dr. Susan Bertram and Dr. Howard Rundle, for providing me with advice when necessary.

I would also like to thank the past and present members of the Godin lab - Heather Auld, Patrick Barks, Pierre-Luc Brackenridge, Adam Densmore, Stacey Lee-Jenkins, Keegan McGrath, Rebecca Warmington, Richard Webster and Alex Wilson - for all of their help and the laughs we have shared. I have enjoyed our time together in and outside of the lab, and I look forward to all of our future adventures. Special thanks go to Stacey, whose assistance in the lab and the field made much of this work possible, and to Keegan for all his help analyzing photos.

Lastly, I would like to thank my friends and family for all of their support and encouragement along the way. Without you none of this would have been possible. 


\section{TABLE OF CONTENTS}

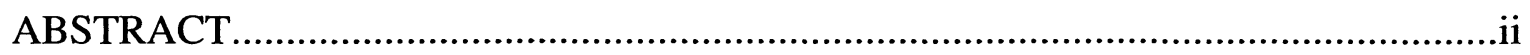

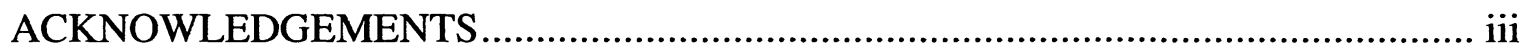

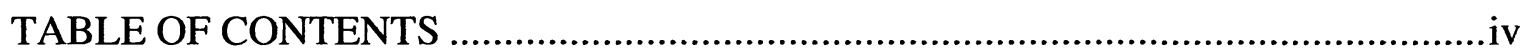

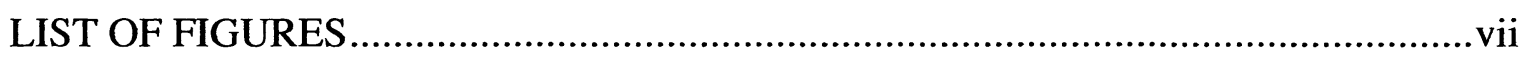

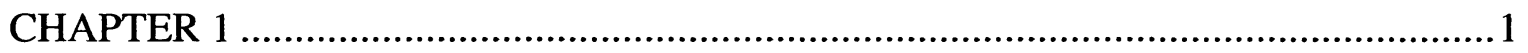

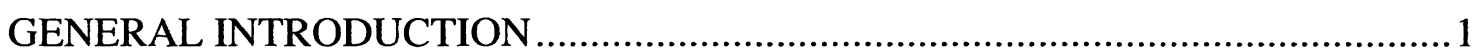

Male mate choice in relation to sperm competition: a general overview ...................1

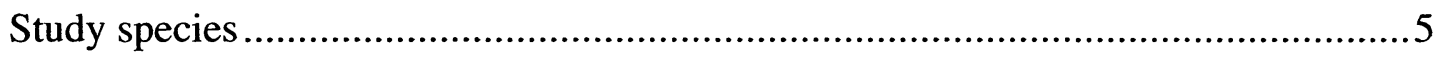

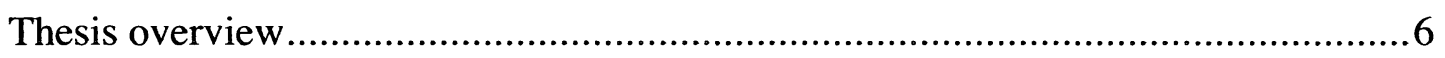

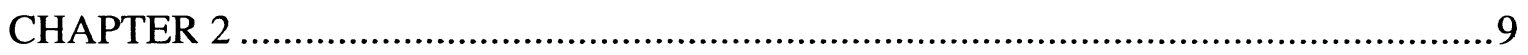

VALIDATION OF A METHOD FOR QUANTIFYING MATING PREFERENCES IN

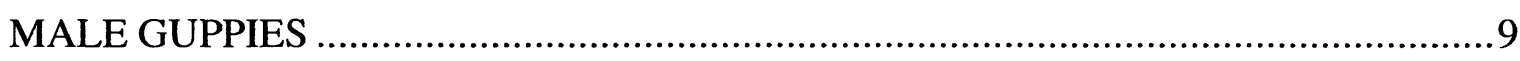

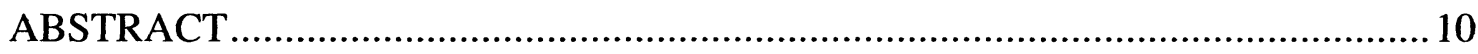

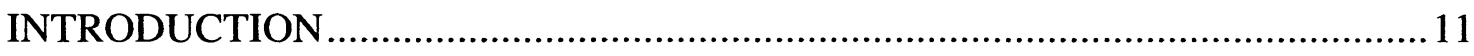

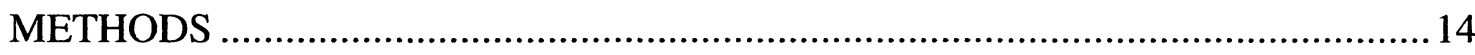

Study Species and Housing .......................................................................... 14

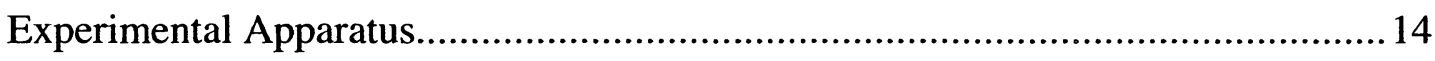

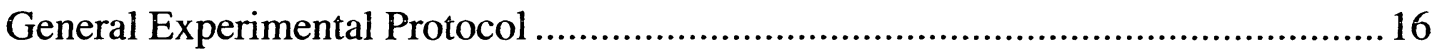

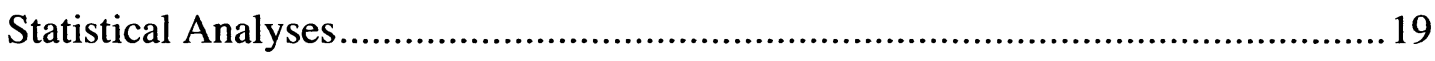

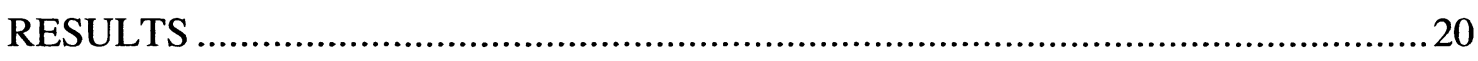

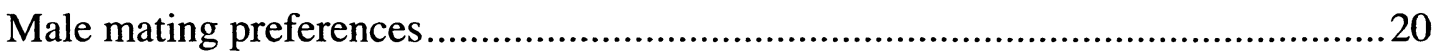

Correlations between sexual behaviours in the two test types ..............................20

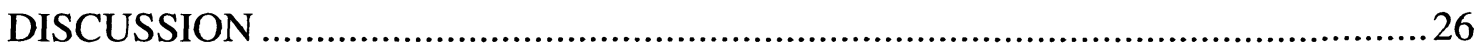




\section{SPERM COMPETITION RISK AND MATE CHOICE IN MALE TRINIDADIAN}

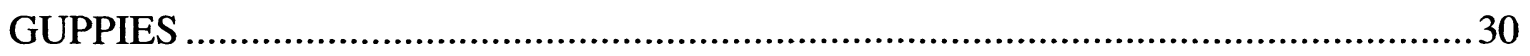

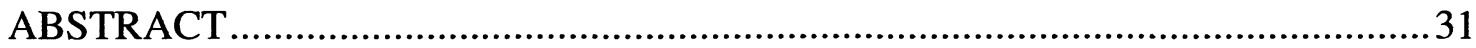

INTRODUCTION

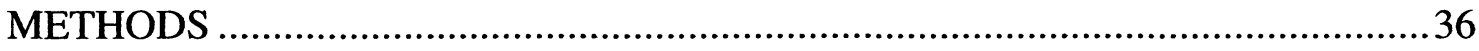

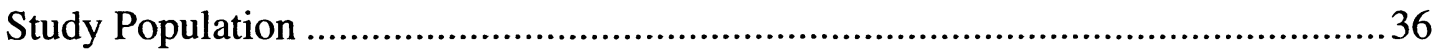

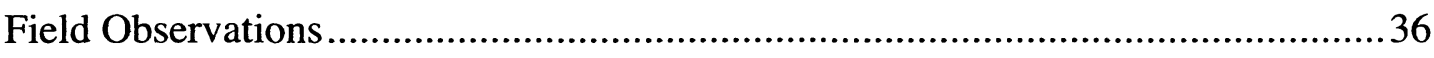

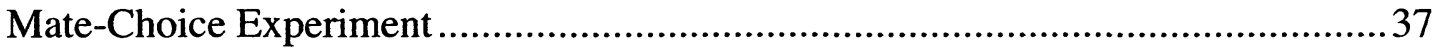

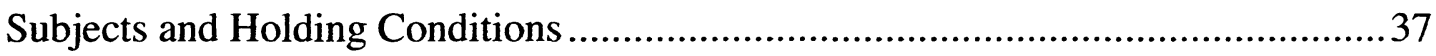

Experimental Apparatus...................................................................................... 37

General Experimental Protocol ........................................................................... 39

Treatment A: No sperm competition risk ........................................................ 42

Treatment B: Presence of a rival male as a cue for SCR ......................................42

Treatment C: Full interaction with a rival male as a cue for SCR .........................43

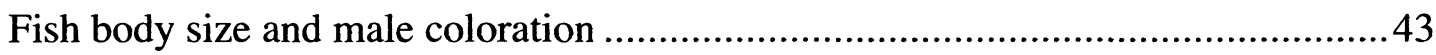

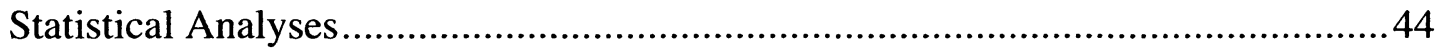

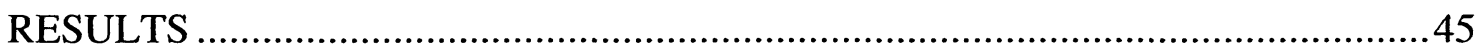

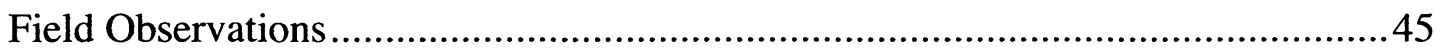

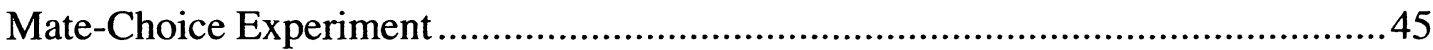

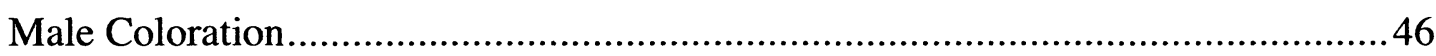

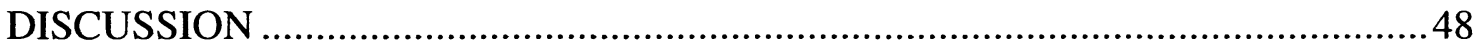

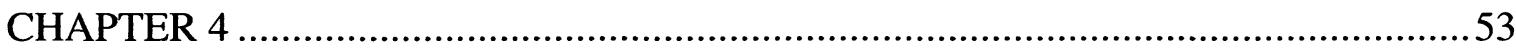

MALE MATE CHOICE IN RELATION TO SPERM COMPETITION AND FEMALE

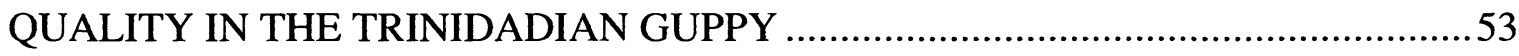

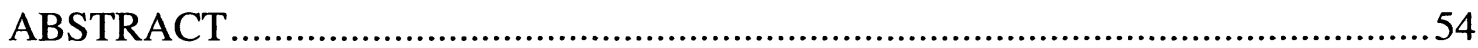

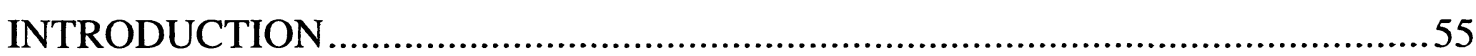

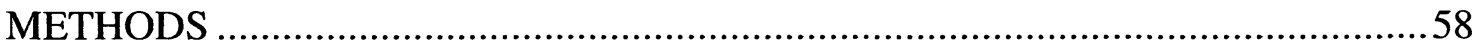




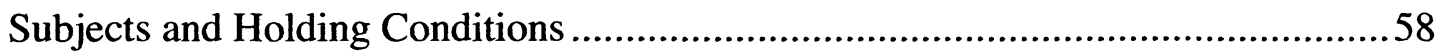

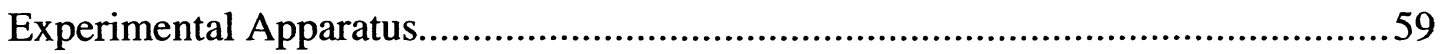

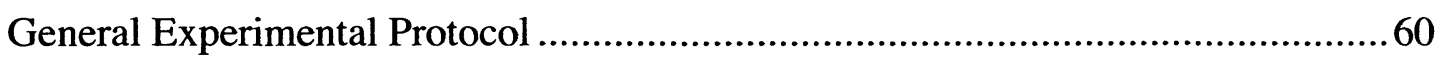

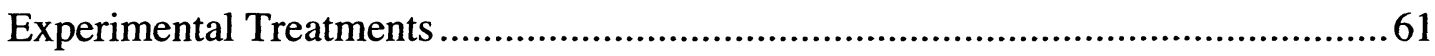

Male Coloration and Fish Body Size...................................................................63

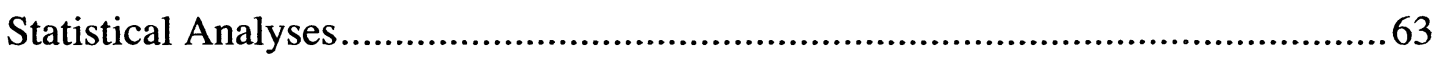

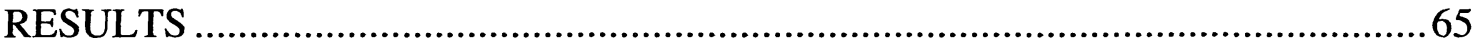

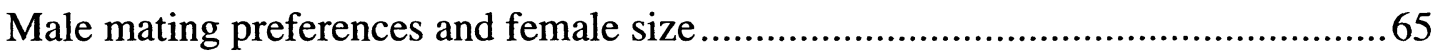

Male mating preferences in relation to sperm competition and female size.............67

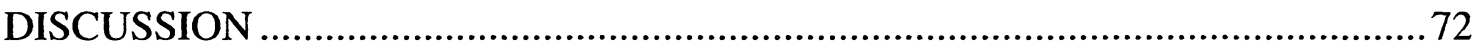

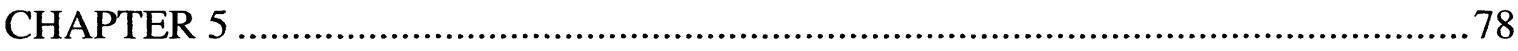

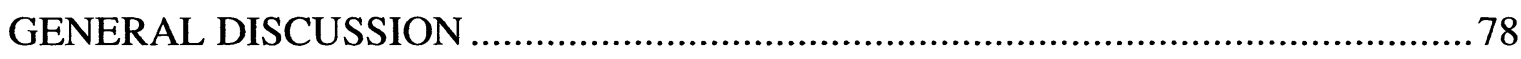

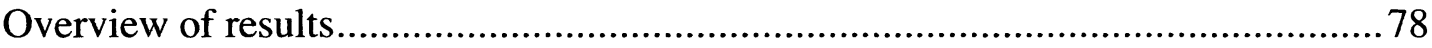

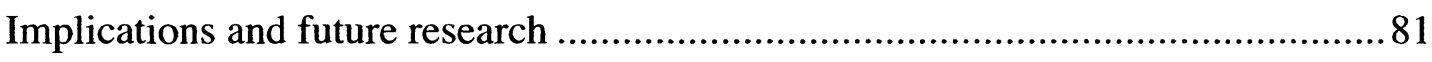

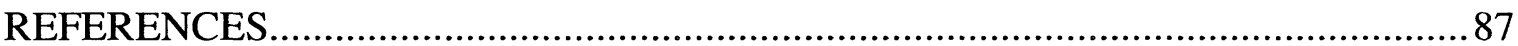




\section{LIST OF FIGURES}

\section{Chapter 2: Validation of a method for quantifying mating preferences in male guppies}

Figure 2.1. Schematic representation of the experimental apparatus, consisting of a central test aquarium and two adjacent end compartments each containing a stimulus female.

Figure 2.2. Relationship between the time individual focal males spent associating with either the larger female (positive scores) or smaller female (negative scores) in the Dichotomous-Choice Test and the time they spent pursuing the same female in the FullInteraction Test.

Figure 2.3. Relationship between the time individual focal males spent associating with either the larger female (positive scores) or smaller female (negative scores) in the Dichotomous-Choice Test and the number of sigmoid displays they directed at the same female in the Full-Interaction Test. 23

Figure 2.4. Relationship between the time individual focal males spent associating with either the larger female (positive scores) or smaller female (negative scores) in the Dichotomous-Choice Test and the number of copulation attempts they directed at the same female in the Full-Interaction Test.

Figure 2.5. Relationship between the time individual focal males spent pursuing and the number of copulation attempts they directed at either the larger female (positive scores) or smaller female (negative scores) in the Full-Interaction Test.

\section{Chapter 3: Sperm competition risk and mate choice in male Trinidadian guppies}

Figure 3.1. Schematic top view of the experimental apparatus. The central aquarium held the focal male and each of the two end compartments held a stimulus female and, depending on the treatment, a rival male or not.....................................

Figure 3.2. Mating preferences of focal males after observing the female preferred in Preference Test 1 either in the absence of any rival male nearby (Treatment A), in the presence of a rival male behind a clear partition (Treatment B), or fully interacting with a

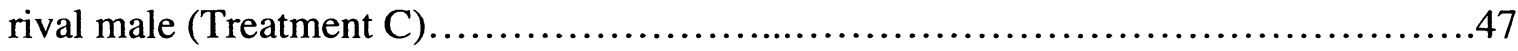

Chapter 4: Male mate choice in relation to sperm competition and female size in the Trinidadian guppy 
Figure 4.1. Mean difference score in the time focal males spent associating with the

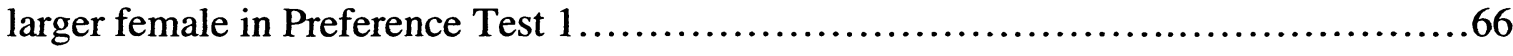

Figure 4.2. Mean difference score in the time focal males spent associating with the initially-preferred female after observing her interacting with either zero, one or two rival

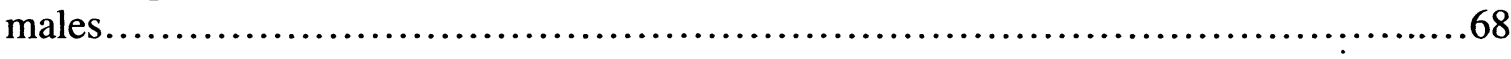

Figure 4.3. Number of focal males that reversed their initial mating preference after observing their initially-preferred female interacting with either zero, one or two rival

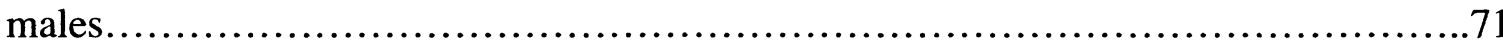




\section{CHAPTER 1}

\section{GENERAL INTRODUCTION}

This thesis explores male mate choice in relation to sperm competition and female quality (potential fecundity). The General Introduction is divided into three sections. In the first section, I provide a general overview of male mate choice theory and how sperm competition can generate variation in female quality, which in turn can lead to males discriminating between females in response to sperm competition. I define key terms, such as sperm competition risk (SCR) and sperm competition intensity (SCI), and introduce the theory underlying the proposition that males may simultaneously evaluate the cost of sperm competition and female quality. I then summarize general information about the study species used in all of my experiments, the Trinidadian guppy (Poecilia reticulata), in the second section. Finally, in the last section, I provide a brief overview of the remaining chapters comprising the thesis.

\section{Male mate choice in relation to sperm competition: a general overview}

Females have traditionally been viewed as the choosy sex, but males may also benefit from being selective in their choice of mates (Dewsbury 1982; Andersson 1994; Simmons 2001; Wedell et al. 2002; Clutton-Brock 2007). Males have a limited supply of energy and therefore several factors can constrain the number of females with which a male can potentially mate. These factors include the costs associated with the production of sperm, searching for females, transferring nutrients to females during copulation, and parental care (Dewsbury 1982; Andersson 1994; Parker et al. 1997; Simmons 2001; 
Wedell et al. 2002; Clutton-Brock 2007). If a male experiences one or more of these costs, then it may pay for him to be selective when females vary in quality. For example, females in a population often vary considerably in their fecundity and males that mate with more fecund females could potentially fertilize more eggs, thereby increasing their reproductive success. Since female fecundity increases with female body size in numerous species, males should adaptively discriminate between females based on size (Andersson 1994). In fact, several studies have reported males preferring larger, more fecund females (e.g. Côté \& Hunte 1989; Nuttall \& Keenleyside 1993; Ptacek \& Travis 1997; Kraak \& Bakker 1998; Dosen \& Montgomerie 2004a; Herdman et al. 2004). In addition to body size, males have also been shown to discriminate between females based on age (Wedell et al. 2002; Muller et al. 2006), social familiarity (Kelley et al. 1999), reproductive status (McLennan 1995; Ojanguren \& Magurran 2004; Deaton 2008) and associated sperm competition risk (Schwagmeyer \& Parker 1990; White \& Galef 1999; Dosen \& Montgomerie 2004b; Wong \& McCarthy 2009). Of this list, my thesis focused primarily on the effect of sperm competition on male mate choice.

Sperm competition occurs when a male's sperm competes with another male's sperm to fertilize a female's eggs (Parker 1970). The probability that a male will have to compete with another male's sperm is termed sperm competition risk (SCR) (Parker et al. 1997), and the number of competing ejaculates is termed sperm competition intensity (SCI) (Parker et al. 1996). For sperm competition to occur, the female has to mate with more than one male and, if she is an internal fertilizer, her reproductive tract must hold the sperm of at least two males at the time of fertilization (Parker 1970; Simmons 2001). Since female monogamy is the exception rather than the rule (Birkhead 2000) and 
females of many species are capable of storing sperm, these criteria are met in numerous species (Birkhead \& Møller 1998; Simmons 2001). Evolutionarily, males have responded to sperm competition with various morphological, physiological and behavioural adaptations. Some of the more extreme examples include the removal of sperm (in the female reproductive tract) from previous males, inserting mating plugs to prevent females from re-mating, and mate guarding that can last months (Simmons 2001). In some species, these tactics may be too costly or not feasible, and therefore males have evolved other strategies.

One such strategy is to vary sperm expenditure in response to perceived sperm competition. Theory predicts that males should increase sperm allocation as SCR increases (Parker et al. 1997), but decrease sperm expenditure as the number of competing males increases above one (Parker et al. 1996). These predictions have been supported by empirical data from a variety of taxa, particularly insects and fishes (Simmons 2001; Wedell et al. 2002). Another potential strategy is to modify mating behaviour in response to sperm competition. Since competing with another male's sperm can decrease the number of eggs a male can potentially fertilize in a given mating, sperm competition can generate variation in female quality. As a result, males could potentially increase their reproductive success by rejecting females that have previously mated (Simmons 2001). Males use a number of cues to predict sperm competition, depending on the species. These cues include, but are not limited to, the duration of pre-copulation mate guarding by the mated male, the amount of sperm in a female, the presence of a mating plug, chemical cues indicating a female's mating status, and socio-sexual cues such as the presence of one or more rival males during or prior to mating (Parker et al. 
1997; Simmons 2001). A handful of studies have investigated the use of socio-sexual cues as predictors of sperm competition. For example, female three-lined ground squirrels (Spermophilus tridecemlineatus) usually mate with two males, and there is cryptic female choice for the first male's sperm that increases with the delay between matings. Males of this species experience high search costs, but as the delay between matings increases, the number of second males that reject a female also increases (Schwagmeyer \& Parker 1990). In birds, male Japanese quail (Coturnix japonica) reverse their mating preference after observing a rival male courting or copulating with their initially-preferred female (White \& Galef 1999). In fishes, male Trinidadian guppies (Poecilia reticulata) and Eastern mosquitofish (Gambusia holbrooki) prefer a female that was previously observed alone to one that was observed interacting with (Dosen \& Montgomerie 2004b), or in the presence of, other males (Wong \& McCarthy 2009), respectively.

I also investigated whether males integrate multiple criteria of female quality. Sperm competition risk and intensity may not be the only quality in which females vary. Therefore, males may simultaneously assess multiple cues of female attractiveness when selecting a mate, and these may trade-off against each other (Galvani \& Johnstone 1998; Reinhold et al. 2002; Ojanguren \& Magurran 2004). As mentioned above, females of several taxa vary in fecundity; therefore, it is likely that a male will receive concurrent information on both a female's fecundity and the immediate SCR or SCI associated with her.

My thesis further contributes to our understanding of the evolution of male mating behaviour in response to socio-sexual cues that may predict SCR and SCI. 


\section{Study species}

I used the Trinidadian guppy as my study system. This species is an important model for the study of sexual selection (Houde 1997; Magurran 2005). The guppy is an internal fertilizing, live-bearing fish. Its mating system is highly promiscuous, and males spend the majority of time pursuing and attempting to mate with females (Magurran \& Seghers 1994). Males achieve copulations either by soliciting females using courtship sigmoid displays or coercing females through sneak gonopodial thrusting (Houde 1997). A courtship sigmoid display involves a male positioning himself in front or slightly to one side of a female, bending his body into an S-shape, and vigorously quivering his entire body for several seconds (Houde 1997). Gonopodial thrusting consists of the male approaching the female from behind, rotating his gonopodium (modified anal fin serving as a sperm intromittent organ) forward $180^{\circ}$, sliding by the female's side, and inserting the tip of the gonopodium into the female's genital pore (Houde 1997). Males can successfully transfer sperm to a female using either of these mating tactics (Pilastro \& Bisazza 1999; Matthews \& Magurran 2000; Evans et al. 2003a).

Female guppies commonly mate with multiple males (Kelly et al. 1999; Becher \& Magurran 2004; Herdman et al. 2004; Neff et al. 2008) and can store sperm for several months (Houde 1997), suggesting that males experience a high SCR. Despite this, male guppies do not physically manipulate females or their reproductive tracts through mate guarding, copulatory plugs, or flushing out the sperm of previous males (Constantz 1984). Instead, males can modify their mating behaviour in response to chemical cues that indicate a female's mating status (Guevara-Fiore et al. 2009; 2010) and socio-sexual cues that may predict SCR (Dosen \& Montgomerie 2004b). However, because the latter 
study was performed on laboratory-reared guppies descended from a Venezuelan population and used a potentially unrealistic number of rival males to simulate an elevated SCR, more research is needed on the potential effect of sperm competition on male mating behaviour in the guppy.

The body sizes of males and females vary widely within natural populations of the guppy (Houde 1997). Males are typically smaller than females and females continue to grow after sexual maturation, whereas males do not (Houde 1997). Fecundity increases with female body size (Reznick \& Endler 1982; Reznick 1983), and there is evidence that males prefer larger females (Dosen \& Montgomerie 2004a; Herdman et al. 2004).

All fish used in my study were collected from the Quaré River, Trinidad $\left(10^{\circ} 41^{\prime} 25^{\prime \prime} \mathrm{N}, 61^{\circ} 11^{\prime} 51^{\prime \prime} \mathrm{W}\right)$ using a hand seine. Fish were maintained in mixed-sex aquaria filled with filtered aged tap water at either the University of the West Indies, St. Augustine, Trinidad or Carleton University, Ottawa, Canada.

\section{Thesis overview}

In this thesis, I investigated the effects of sperm competition and female quality (potential fecundity) on male mating tactics in the Trinidadian guppy. In Chapter 2, I validated the laboratory-based experimental method (dichotomous-choice test) that was used for all of my experiments. I tested whether male association times (with either of two stimulus females presented) recorded in a dichotomous-choice test corresponded with male mating behaviour directed at the same females when the male was allowed to swim freely with them. 
In Chapter 3, I tested whether males use socio-sexual cues as a reliable indicator of SCR and modify their mating behaviour accordingly. To determine the number of rival males that may predict SCR in nature, I performed visual focal observations (cf. Martin \& Bateson 1986) of free-ranging adult female guppies in the Quaré River, Trinidad (my study population). The most commonly observed number of rival males in the field was then used to simulate ecologically-relevant SCR in my laboratory behavioural experiments. In laboratory tests, I presented individual males with a choice between two adult females of similar size and reproductive status as potential mates. After ascertaining a focal male's initial mating preference, I then simulated an elevated SCR associated with the initially-preferred female and tested the male's mating preference again. I also determined which social cues a male uses as reliable predictors of SCR, specifically whether a male uses the mere presence of a rival male or his observation of a rival male fully interacting with the female to assess his immediate risk of sperm competition.

In Chapter 4, I investigated male mate choice in response to SCR, SCI and female quality (potential fecundity, as measured by body size). I concurrently manipulated SCR/SCI and the potential fecundity of the paired females to determine whether males are able to simultaneously evaluate these cues of female quality. To titrate SCI, I used the numbers of males that were most commonly observed pursuing a female in the wild (Chapter 3). To manipulate relative female fecundity, I presented focal males with either two females matched for body size or two females that differed considerably in body size. 
In the final Chapter 5, I summarize my salient results and highlight their contribution to our understanding of the evolution of mate choice in males and their strategic behavioural responses to sperm competition. I also identify a few potentially fruitful areas for future research, which logically follow from my results here. 


\section{CHAPTER 2}

VALIDATION OF A METHOD FOR QUANTIFYING MATING PREFERENCES IN MALE GUPPIES 


\begin{abstract}
Male and female mating preferences are commonly inferred from association times measured in a dichotomous-choice test, but this experimental method is rarely validated. Using the Trinidadian guppy (Poecilia reticulata), I tested whether a male's mating preference for either of two stimulus females, as measured in a dichotomous-choice test, correlated with his mating behaviours directed at the same female when he was allowed to swim freely with both females. Male mating preference was first measured in a dichotomous-choice test in which the male could only use visual cues alone to assess the paired females. This was done by quantifying the duration of time focal males spent associating with each female. Immediately following this test, the focal male was allowed to swim freely with both females, and the time he spent pursuing each female and the number of courtship sigmoid displays and copulation attempts he directed at each female were quantified. Male association time in the dichotomous-choice test was significantly positively correlated with both the time spent pursuing and the number of courtship sigmoid displays directed at the same female initially preferred in the dichotomous-choice test. Association time in the dichotomous-choice test was not correlated with the number of copulation attempts, but the number of copulation attempts was significantly positively correlated with the duration of time spent pursuing the same female. Collectively, these results confirm that association time measured in a dichotomous-choice test is a reliable predictor of male mating preferences in the Trinidadian guppy.
\end{abstract}




\section{INTRODUCTION}

As discussed in Chapter 1, females have traditionally been viewed as the choosy sex, and female mate choice for elaborate male traits has been widely studied (Andersson 1994). More recently, however, it has been suggested that males may also benefit from being choosy (Dewsbury 1982; Andersson 1994; Simmons 2001; Wedell et al. 2002; CluttonBrock 2007), which has resulted in several studies reporting male mate choice in a variety of taxa (e.g. Côté \& Hunte 1989; Nuttall \& Keenleyside 1993; Ptacek \& Travis 1997; Kraak \& Bakker 1998; White \& Galef 1999; Wedell et al. 2002; Dosen \& Montgomerie 2004a; Herdman et al. 2004; Muller et al. 2006). As the number of studies on male mate choice is increasing, it is important to develop and validate effective methodologies for assessing male mating preferences. Therefore, before addressing the main question of my thesis on whether variation in sperm competition and female quality affect male mate choice in the Trinidadian guppy, I wished to validate my chosen method for quantifying male mating preferences in this species.

For my study, I chose a laboratory-based method that is commonly used to test both male and female mate preferences, known as the dichotomous-choice test. During a trial, the focal male or female is given a choice between two potential mates that are physically separated from each other and the focal individual (Houde 1997). The amount of time the focal individual spends near (= socially associates with) each of the two potential mates is recorded, and either absolute time (e.g. Kodric-Brown 1989; Dosen \& Montgomerie 2004b), a difference score (e.g. Dosen \& Montgomerie 2004a; Herdman et al. 2004; Hoysak \& Godin 2007), or a percentage of the total time spent with both stimulus individuals (e.g. Schlupp \& Ryan 1997; Wong \& McCarthy 2009) is calculated 
as a measure of the focal individual's mating preference. This method has many advantages; for example, it prevents any aggression or other behavioural interactions between the two stimulus males or females from confounding the focal subject's preference, focal individuals can be tested individually, and the results are easy to analyze and interpret (Houde 1997; Wagner 1998). Another benefit of this method specific to my thesis project is that stimulus fish, such as rival males, can easily be added to and removed from stimulus fish compartments with minimal disturbance to the focal individual during the course of a trial.

There are, however, criticisms of this particular method. For example, the potential mates are compared simultaneously side-by-side instead of sequentially, which may be more natural in some systems (Wagner 1998). In the Trinidadian guppy (Poecilia reticulata), however, males are likely able to simultaneously evaluate at least two females since guppies swim in mixed-sex shoals (Houde 1997). Another criticism is that social association time is not a direct observation of sexual behaviour and therefore may not represent mating preference (Houde 1997; Gabor 1999). Interestingly, despite these criticisms and its common use in mate choice studies, the dichotomous-choice method is rarely validated for the species under investigation (but see Bischoff et al. 1985; Kodric-Brown 1989; Clayton 1990; Ryan et al. 1990; Cummings \& Mollaghan 2006; Witte 2006; Lehtonen \& Lindström 2008; Walling et al. 2010). This is particularly true of male mate choice studies, even though several of them use association time to assess mating preferences (e.g. Dosen \& Montgomerie 2004a; Plath et al. 2008; Wong \& McCarthy 2009).

The few studies that have tested whether association time correlates with actual 
mate choice used a variety of protocols. A common approach is to allow the focal individual to fully interact with one or both of the stimulus subjects following the dichotomous-choice test. Preference in a subsequent full-interaction test is usually determined by scoring the number of matings (Lehtonen \& Lindström 2008), pair formation (Clayton 1990), reproduction (Walling et al. 2010) or mating displays (Cummings \& Mollaghan 2006) exhibited by the focal individuals towards the potential mates. The results from both the dichotomous-choice and full-interaction tests are then compared. The latter measurement is feasible using male guppies since they spend a significant amount of time pursuing females and perform mating displays to solicit copulations in nature (Magurran \& Seghers 1994).

The Trinidadian guppy is an important model species for the study of sexual selection (Houde 1997; Magurran 2005) and several studies investigating mating preferences in this species have used the dichotomous-choice method (Houde 1997). Previous studies of female guppy mating preferences have already shown that males with traits preferred in dichotomous-choice tests also gain more copulations when allowed to swim freely with a female (Bischoff et al. 1985; Kodric-Brown 1989). However, it has not yet been shown that association time in a dichotomous-choice test is an appropriate proxy for male mating preference in this species. Here, I tested whether the duration of time a focal male spends associating with stimulus females in a dichotomous-choice test correlates with his mating behaviours directed at the same females when the fish are allowed to freely interact in an open arena. 


\section{METHODS}

\section{Study Species and Housing}

Wild-caught Trinidadian guppies from the Quaré River, Trinidad (1041'25” N, $61^{\circ} 11$ '51"W) were used in this experiment. Test fish were held in mixed-sex aquaria and fed commercial flake food and live brine shrimp (Artemia sp.) twice daily. The holding aquaria were filled with filtered aged tap water maintained at $24-26^{\circ} \mathrm{C}$ and illuminated with overhead fluorescent lights on a $13 \mathrm{~h} \mathrm{~L}: 11 \mathrm{~h}$ D cycle. Two weeks before the behavioural trials, two 60 -litre housing aquaria were set-up, each with a 2 female : 1 male sex ratio at densities of 15 to 21 fish. Since guppies can become familiar with each other after 12 days of association (Magurran 2005), the focal male and the two stimulus females used in any given mating preference trial were taken from different holding aquaria. Behavioural trials were completed within 10 days, after which the housing aquaria were replenished with new males. Because of the limited availability of adult females $(N=41)$, some were necessarily used as stimulus females more than once, but never on the same day.

\section{Experimental Apparatus}

The experimental apparatus consisted of a central test aquarium $(40 \times 20 \times 25 \mathrm{~cm} ; \mathrm{L} \times \mathrm{W}$ x H), flanked by a clear Plexiglas compartment $(15 \times 20 \times 22 \mathrm{~cm})$ on either end (Fig. 2.1). The test aquarium held the focal male. Vertical lines, drawn on the front and back walls $10 \mathrm{~cm}$ from either end of this tank, demarcated mating preference zones. Each of the two end compartments held a stimulus female. This design allowed for the testing of male mating preferences based on female visual cues alone and for the positions of the end compartments to be switched without handling the fish. For the preference tests that 


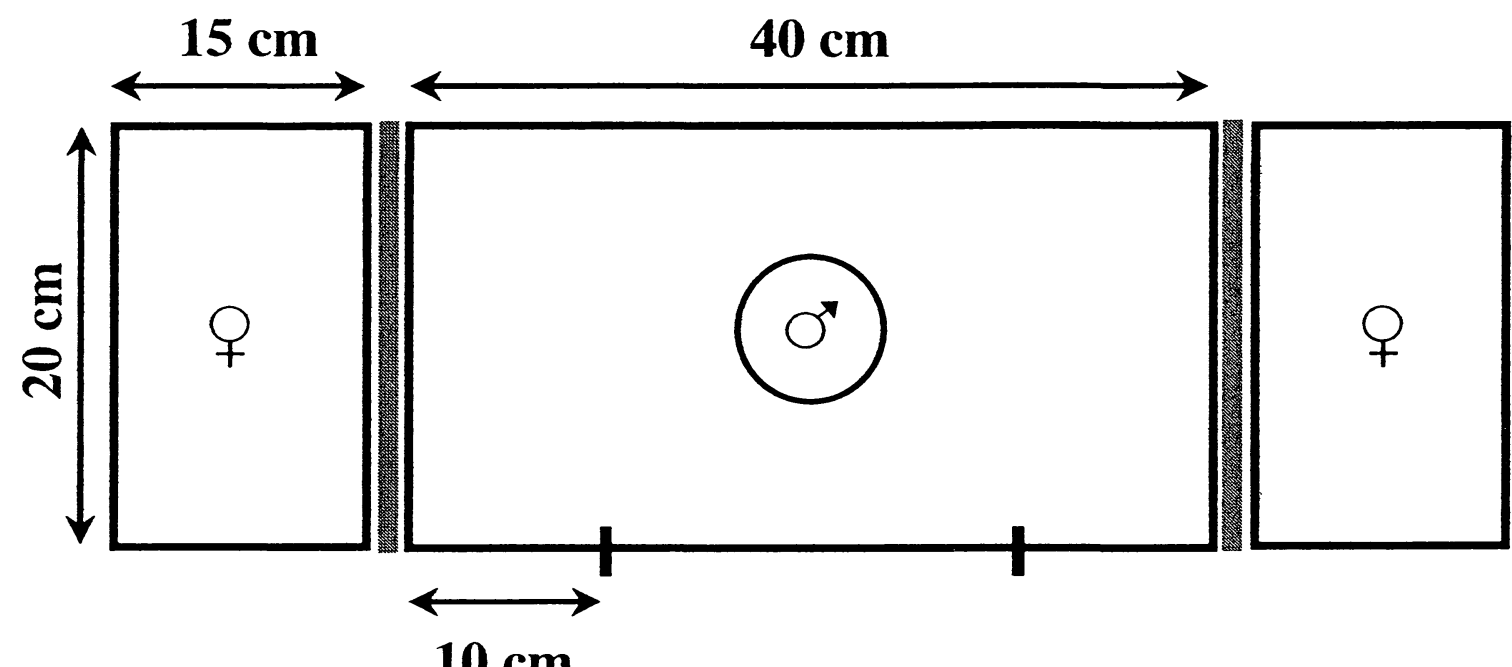

Figure 2.1. Schematic representation of the experimental apparatus, consisting of a central test aquarium and two adjacent end compartments each containing a stimulus female. During the Dichotomous-Choice Test, the central aquarium held the focal male, whereas during the Full-Interaction Test it held the focal male and stimulus females. The circle represents a removable clear Plexiglas tube (which contained the focal male during the acclimatization periods) and the shaded lines represent opaque screens that were removed during viewing and choice tests. The tick marks denote the outer edge of the $10-\mathrm{cm}$ preference zones. 
allowed full-interaction between the male and stimulus females, only the central aquarium was used.

The bottom of the test aquarium and end compartments was covered with aquarium gravel. The back wall of the test aquarium and three sides of the stimulus compartments were covered internally with brown plastic corrugated board to provide a uniform visual background and reduce external disturbances. The test aquarium and end compartments were filled with $15 \mathrm{~cm}$ of aged tap water maintained at $24-26^{\circ} \mathrm{C}$ and illuminated overhead with fluorescent tubes. The behaviour of the fish was viewed using a digital HD video camera (Sony HandyCam HDR-HC7) placed approximately $50 \mathrm{~cm}$ in front of the central test aquarium and covered by a blind to prevent any external disturbance to the fish. The video image was displayed on a remote monitor and the time spent by the focal male in each preference zone was scored in real time, whereas the fullinteraction preference tests were recorded on tape and scored blind at a later date.

\section{General Experimental Protocol}

All trials consisted sequentially of a binary-choice test in which the focal male was given a choice between two females based on visual cues alone (Dichotomous-choice Test), followed immediately by a free-swimming preference test in which the focal male was allowed to fully interact with the stimulus females (Full-Interaction Test).

The day before a trial, males were isolated from females to give them sufficient time to replenish their sperm reserves and to ensure that all males were similarly sexually motivated at the onset of the behavioural trials. 


\section{Acclimatization period}

On the day of a trial, the standard body lengths of two adult gravid females, matched by eye as closely as possible in abdominal distension, were measured without anesthesia, and one stimulus female was placed in each of the two end compartments. The average ( \pm $S E)$ standard body length of the stimulus females was $27.1 \mathrm{~mm}( \pm 0.44$, range $=23.5-$

$32.0 \mathrm{~mm}, N=52$ ). In any given trial, the paired stimulus females were chosen to differ in body length by $4.6 \mathrm{~mm}$ on average $( \pm 0.19$, range $=3.2-6.5 \mathrm{~mm}, N=26)$ to facilitate male mate choice (Dosen \& Montgomerie 2004a; Herdman et al. 2004) and to visually distinguish them during the Full-Interaction Test (see below). The position of the endcompartment containing the larger female was alternated between trials. A focal male was then introduced into the test aquarium and all fish were left undisturbed to acclimatize for $10 \mathrm{~min}$, during which time opaque screens between the central aquarium and the end compartments blocked the focal male's view of the females.

\section{Dichotomous-Choice Test}

The focal male's mating preference was first tested in a dichotomous-choice test. The focal male was gently dip-netted and placed in a clear Plexiglas tube $(7 \mathrm{~cm}$ diam.) in the centre of the test aquarium. The opaque screens were then removed, allowing the male to observe the stimulus females for $10 \mathrm{~min}$. Following this viewing period, the focal male was released from the Plexiglas tube for an initial 10-min choice test. The time the male spent in each preference zone, and facing $\left(0 \pm 90^{\circ}\right)$ the female in the end compartment, was recorded. To control for any potential side bias, the end compartments were switched at the end of this first choice test, and the viewing period and choice test were 
then repeated. The focal male's mating preference was taken as the sum of the time he spent near either stimulus female over $20 \mathrm{~min}$ (= two consecutive 10-min choice tests). Gonopodial extension, in which the male swung his gonopodium forward at least $90^{\circ}$, and courtship sigmoid displays (Houde 1997) directed at the females were also recorded.

\section{Full-Interaction Test}

Immediately following the Dichotomous-choice Test, the opaque screens were replaced and the central test aquarium was temporarily divided in half with a clear Plexiglas partition. Both stimulus females were then gently dip-netted into a small container with water and transferred to the central test aquarium on the opposite side of the partition holding the focal male. All fish were left undisturbed for $10 \mathrm{~min}$ to allow the females to acclimatize to the aquarium and for the focal male to view the females. After this period, the partition was raised and the behaviour of the fish was recorded on video for 20 min. At the end of the trial, the standard body length of the focal male was measured . A total of 33 males were tested individually. The average length of focal males was $17.2 \mathrm{~mm}$ ( \pm $0.17,16.0-19.8 \mathrm{~mm})$

The behaviour of focal males was scored from the video tapes using JWatcher (Blumstein \& Daniel 2007). The following male sexual behaviours were recorded: the number and duration of sexual pursuits, defined as a male actively following a female or hovering within 1-3 body lengths of a female with his head oriented towards her; the number of unambiguous sigmoid displays directed at a female; and the number of copulation attempts. 


\section{Statistical Analyses}

Descriptive statistics are reported as the mean $( \pm S E$, range, $N)$. Following Dosen $\&$ Montgomerie (2004a) and Herdman et al. (2004), separately for each male behavioural measure recorded, a difference score was calculated by subtracting the value of the behaviour directed towards the smaller female from that directed towards the larger female. A positive difference score indicates a preference for the larger female and conversely a negative score indicates a preference for the smaller female. The relationship between the time spent by focal males with the larger female relative to the smaller one (i.e. difference preference score) in the Dichotomous-Choice Test and the difference score for each of their recorded sexual behaviours directed towards the paired females in the Full-Interaction Test was determined separately using the Spearman rank correlation.

Trials were excluded from the analysis if either the focal male showed a side-bias (defined as spending more than $80 \%$ of his time in one preference zone), one of the females did not resume normal swimming and pressed against a side wall or sank to the substrate, or the focal male appeared stressed or unhealthy. A total of seven trials were not included in the analysis. 


\section{RESULTS}

During the Dichotomous-Choice Test, all focal males $(N=26)$ spent time associating with both of the paired stimulus females. Whilst in the preference zone associated with a particular female, approximately $70 \%$ of the males exhibited gonopodial extensions and $30 \%$ performed sigmoid displays toward the female. In the Full-Interaction Test, all focal males sexually pursued and the majority courted (with sigmoid displays) the females, but none of the females were responsive to male sexual solicitations. All but two of males also performed sneak copulation attempts, but none of these attempts resulted in a successful copulation.

\section{Male mating preferences}

The mating preference of focal males varied widely, ranging from some males strongly preferring the larger female to other males strongly preferring the smaller female (Fig. 2.2). On average, however, the males did not show a significance preference for either the larger or the smaller female in the Dichotomous-Choice Test (association time: Wilcoxon signed ranks test: $\mathrm{Z}=-0.952, P=0.34, N=26$ ) or in the Full-Interaction Test (duration of sexual pursuits: Wilcoxon test: $Z=-1.206, P=0.23, N=26$; sigmoid displays:

Wilcoxon test: $\mathrm{Z}=-1.156, P=0.25, N=15$; copulation attempts: Wilcoxon test: $\mathrm{Z}=$ $1.223, P=0.22, N=24)$.

\section{Correlations between sexual behaviours in the two test types}

Notwithstanding the above results, there was a significant positive correlation between the time a male spent associating with the preferred female (either the larger or smaller 
one) in the Dichotomous-Choice Test and both the time he spent pursuing her (Spearman rank correlation: $r_{s}=0.57, P=0.002, N=26$; Fig. 2.2) and the number of sigmoid displays he directed at her (Spearman rank correlation: $r_{s}=0.56, P=0.03, N=15$; Fig. 2.3) during the Full-Interaction Test. The amount of time a male spent associating with the preferred female in the Dichotomous-Choice Test was not significantly correlated with the number of copulation attempts he directed at the same female in the FullInteraction Test (Fig 2.4). There was, however, a strong positive relationship between the total duration of a focal male's sexual pursuits of the preferred female and the frequency of his copulation attempts towards her (Spearman rank correlation: $r_{s}=0.72, P$ $<0.001, N=24$; Fig. 2.5). 


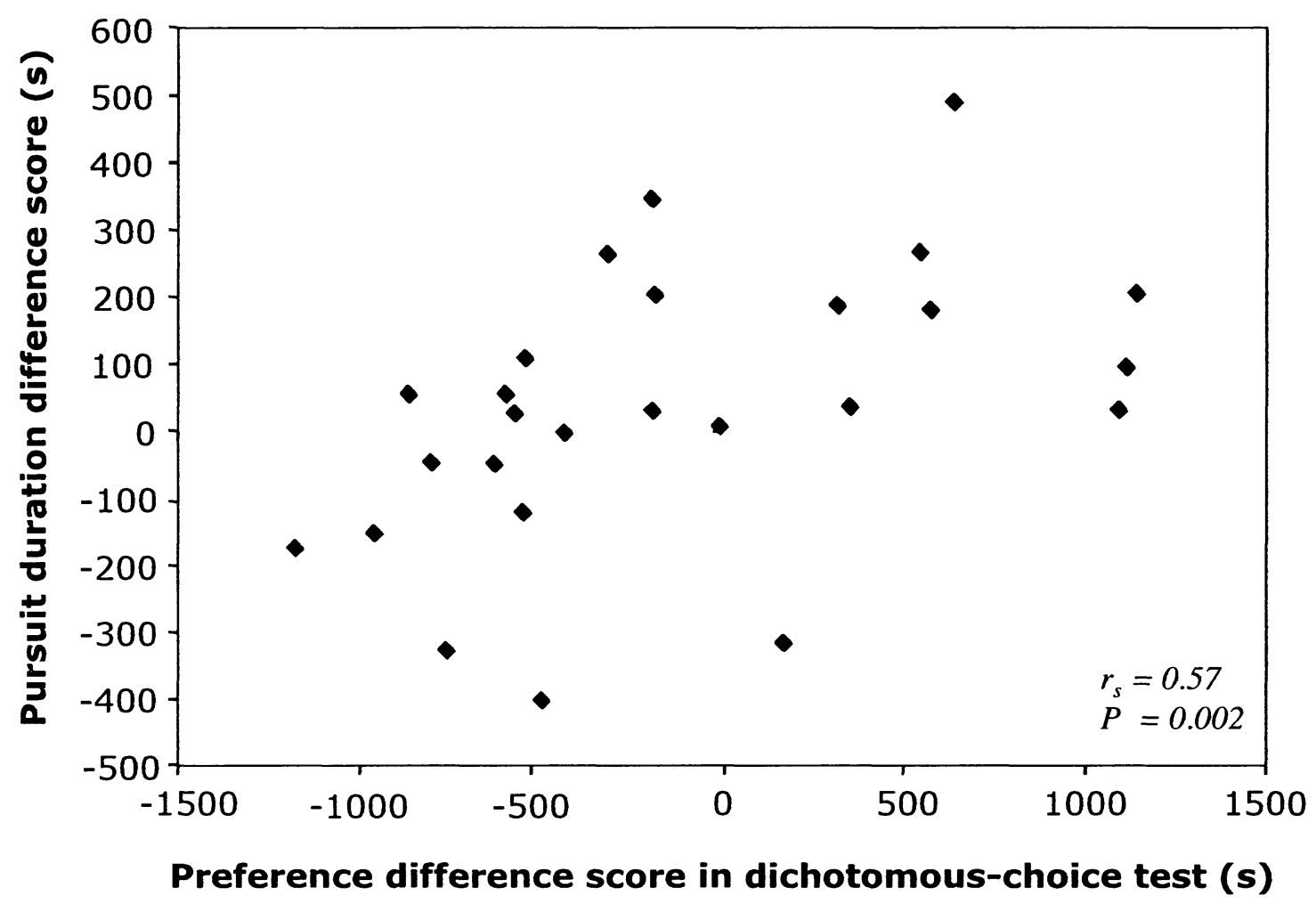

Figure 2.2. Relationship between the time individual focal males spent associating with either the larger female (positive scores) or smaller female (negative scores) in the Dichotomous-Choice Test and the time they spent pursuing the same female in the FullInteraction Test. The statistic shown was obtained using the Spearman rank correlation test. 


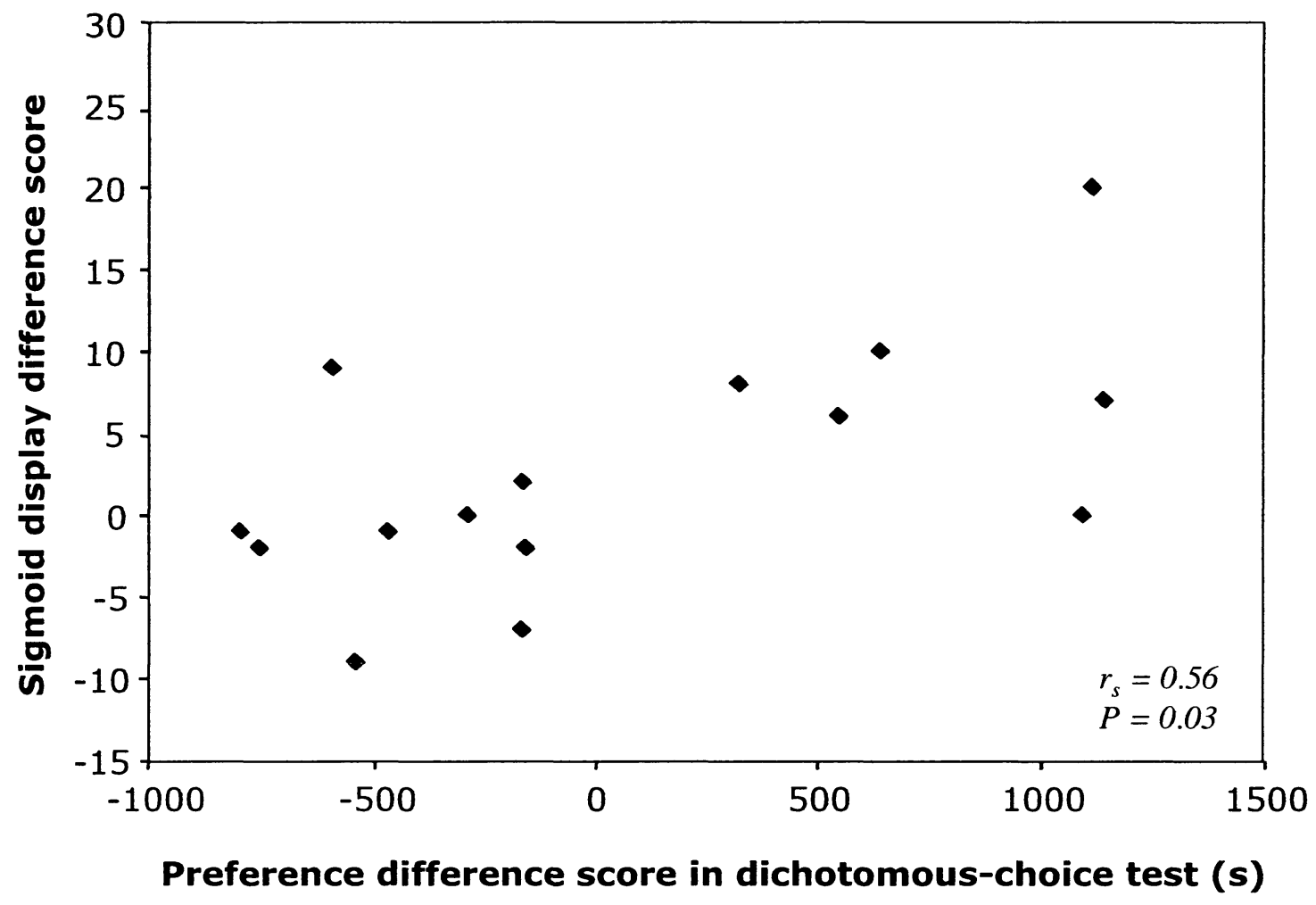

Figure 2.3. Relationship between the time individual focal males spent associating with either the larger female (positive scores) or smaller female (negative scores) in the Dichotomous-Choice Test and the number of sigmoid displays they directed at the same female in the Full-Interaction Test. The statistic shown was obtained using the Spearman rank correlation test. 


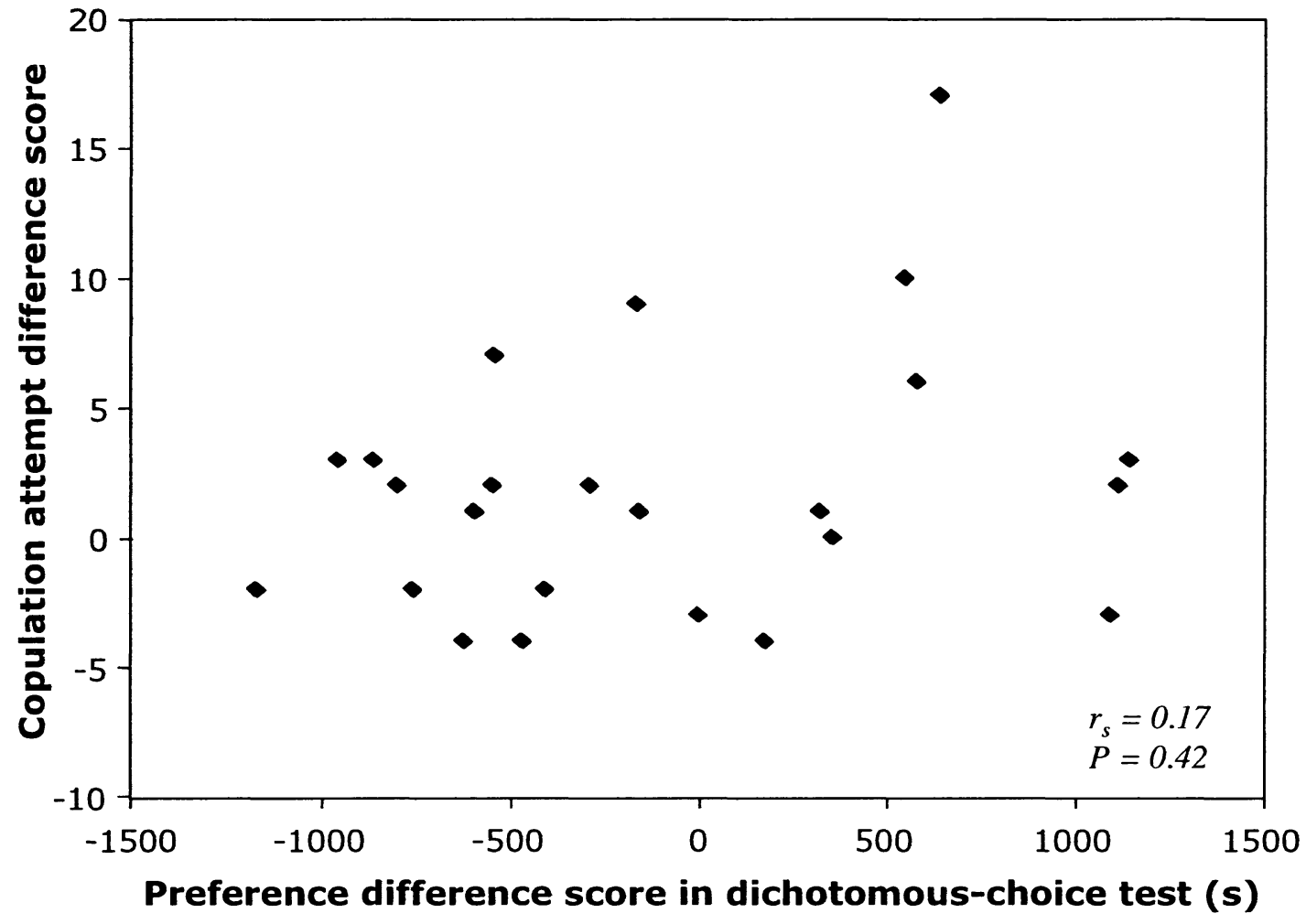

Figure 2.4. Relationship between the time individual focal males spent associating with either the larger female (positive scores) or smaller female (negative scores) in the Dichotomous-Choice Test and the number of copulation attempts they directed at the same female in the Full-Interaction Test. The statistic shown was obtained using the Spearman rank correlation test. 


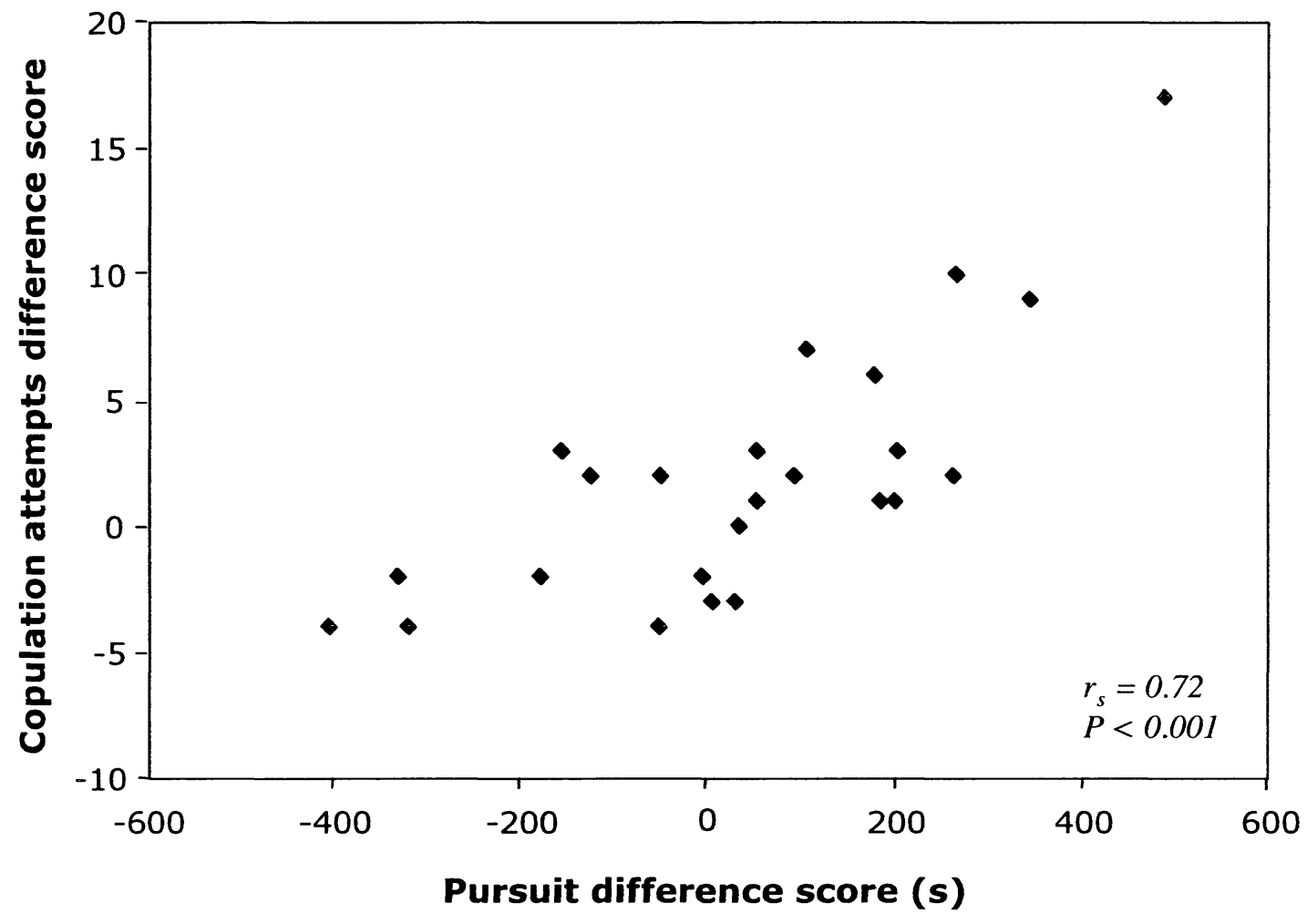

Figure 2.5. Relationship between the time individual focal males spent pursuing and the number of copulation attempts they directed at either the larger female (positive scores) or smaller female (negative scores) in the Full-Interaction Test. The statistic shown was obtained using the Spearman rank correlation test. 


\section{DISCUSSION}

Collectively, my results validate the use of male association time with females in the Dichotomous-Choice Test (only female visual cues available) as an appropriate proxy for male mate choice in the Trinidadian guppy. During the Dichotomous-Choice Test, the majority of focal males performed gonopodial extensions, a typical behaviour associated with male mating attempts (Houde 1997), and approximately one third of the males even courted (with sigmoid displays) the stimulus females that were restrained in the end compartments. In addition, the amount of time a male spent with a female in the Dichotomous-Choice Test was significantly positively correlated with both the amount of time he spent pursuing the same female and the number of sigmoid displays directed at her in the Full-Interaction Test. Although male association time and the number of copulation attempts were not significantly correlated, male sexual pursuit time was significantly positively correlated with the number of copulation attempts in the FullInteraction Test. For this reason, pursuit duration and the number of sigmoid displays are arguably more reliable measures of male mating preference.

In the current experiment, male guppies did not show a significant preference, on average, for the larger of the two stimulus females, either in the Dichotomous-Choice Test or the Full-Interaction Test, as shown previously in other studies on the guppy (Dosen \& Montgomerie 2004a; Herdman et al. 2004). As with fishes in general, larger female guppies are more fecund (Reznick 1983), and therefore it is expected that males should prefer to mate with larger females, everything else being equal (Andersson 1994). In contrast to my results here, Dosen \& Montgomerie (2004a) found that male guppies 
(lab-born and from a Venezuelan population) preferred larger females in DichotomousChoice Tests, which strengthened as the size difference between the two females increased. They also reported, however, that the preference for larger females appeared to dissolve when the difference between paired stimulus females was about $4 \mathrm{~mm}$, and that males started to prefer the smaller female at size differences less than $4 \mathrm{~mm}$. The median size difference used in my experiment was $4.25 \mathrm{~mm}$ (ranging from 3.2 to 6.5 $\mathrm{mm}$ ) and, in this respect, my results are somewhat similar to those reported by Dosen \& Montgomerie (2004a). It is unknown why male guppies would lose their preference for the larger female at this particular size difference. One possibility is that they cannot detect such difference in size between paired females, but this seems unlikely. Another possibility is that there is less of a reproductive advantage to a male in preferring the larger of two females as a mate when they differ in body length by only $4 \mathrm{~mm}$ or less, and under this situation males are selecting females using a criterion or criteria other than body length. The main objective of my study though was to determine whether male association time with females exhibited in a Dichotomous-Choice Test predicts male mate choice when males are allowed to interact freely with females in the Trinidadian guppy. The particular range of size differences between paired stimulus females used in the current experiment was not chosen a priori to test male mating preference for large females per se, but more so to allow the observer to distinguish between the two females when scoring behaviours during the Full-Interaction Test.

Unfortunately, the current experiment was not able to show that male guppies are more likely to mate with the female that they preferred in the Dichotomous-Choice Test. A few studies of female mate choice have used the number of copulations to validate 
dichotomous-choice tests (Bischoff et al. 1985; Kodric-Brown 1989; Lehtonen \& Lindström 2008), but this has never been directly tested using male Trinidadian guppies. There are data from other studies suggesting that male guppies mate more with females that have the same phenotype that is preferred in dichotomous-choice tests. For example, males prefer larger females in dichotomous-choice tests (Dosen \& Montgomerie 2004a) and larger females give birth to broods with more sires (Becher \& Magurran 2004; Herdman et al. 2004); however, this is only anecdotal evidence and an experiment that directly tests whether a correlation really exists is needed. This may prove difficult due to confounding factors, such as female behaviour. Female guppies show mating preferences themselves (Houde 1997), and their responsiveness to males also depends on their reproductive stage (Houde 1997). Virgin and post-parturition females are much more receptive to male sexual behaviours than gravid females (Houde 1997); however, even virgin females will not always copulate during a trial (Houde 1997), which would increase the number of fish needed for an experiment. Another factor that would influence the design of a mate-choice experiment is that male guppies significantly decrease their sexual activity after copulation (Pilastro \& Bisazza 1999), and therefore a longer observation time may be needed to score more than one copulation. For these reasons, it would be much more practical and preferable to be able to infer male mating preferences from their courtship displays and the amount of time spent sexually pursuing a female than from the number of copulations.

In conclusion, my results validate the use of male association times with females in a dichotomous-choice test as a reliable proxy measure of male mate choice in the Trinidadian guppy. The current study is the first to demonstrate this for male guppies, 
and is amongst only a few studies to date to have done so for animals in general. The majority of male guppies in the current experiment showed a strong preference for one of the two stimulus females, but as a group did not prefer the larger of the two females; however, this was most likely due to the relatively small female size differences used in this experiment. Future studies aiming to test whether male mating preferences for larger females trade-off against other measures of female quality should therefore use a larger size difference between paired stimulus females than used in the current study. 


\section{CHAPTER 3}

SPERM COMPETITION RISK AND MATE CHOICE IN MALE TRINIDADIAN GUPPIES *

" Chapter based on a manuscript currently under review in Anim. Behav. 


\begin{abstract}
Sperm competition theory predicts that males should be sensitive to socio-sexual cues that provide information about the risk of sperm competition at any mating and correspondingly adjust their mating tactics in a manner that maximizes their reproductive success. Here, I investigated male mating preferences in response to socio-sexual cues as predictors of sperm competition risk (SCR) in the Trinidadian guppy (Poecilia reticulata) as a model study species. In a natural Trinidadian population, I observed that freeranging females were most commonly pursued sexually by only one male at a time, which presumably represents a SCR associated with that female from the vantage of a nearby male observer. I tested whether wild-caught male guppies would modify their initial mating preference for either of two stimulus females presented by experimentally increasing the male's apparent SCR. This was done by allowing focal males to observe a rival male either placed near (but not physically interacting nor copulating with) or sexually consorting and potentially copulating with their initially-preferred female. In the absence of any apparent increase in SCR, the preference of focal males for either of the two stimulus females presented remained consistent. However, males significantly reduced their preference for their initially-preferred female after having observed her consorting with or merely in the vicinity of a rival male. The results suggest that male guppies are sensitive to perceived SCR and adjust their mate-choice behaviour in an apparently adaptive manner, as predicted by sperm competition theory.
\end{abstract}




\section{INTRODUCTION}

In species with conventional sex roles, females are typically the choosier sex and exhibit mate choice (Andersson 1994). Although male mate choice has been observed in diverse taxa (e.g. Andersson 1994; Bonduriansky 2001; Wedell et al. 2002; Clutton-Brock 2007), our understanding of its evolution is limited compared with or understanding of female mate choice. Males are expected to be discriminating and to exhibit mate choice whenever (i) they invest in parental care, (ii) they have multiple females to choose from, (iii) females vary in quality, (iv) their sperm reserves are diminished by a recent mating with any female, thereby subsequently reducing their chances of fertilizing other females in the short term, and (v) they face a risk of sperm competition (Andersson 1994; Simmons 2001; Wedell et al. 2002; Clutton-Brock 2007). Among these factors, the effect of variation in female quality (i.e. fecundity) on male mate choice has received most attention to date, with males tending to prefer to mate with larger, more fecund females (e.g. Ptacek \& Travis 1997; Kraak \& Bakker 1998; Dosen \& Montgomerie 2004a). How males adjust their mating tactics in response to sperm competition risk is a subject of only relatively recent, but increasing, interest (Wedell et al. 2002).

Sperm competition risk (SCR) is a cost of mating for males; it is defined as the probability that a focal male's sperm will compete against the sperm from other males for a given set of ova (Parker et al. 1997; Simmons 2001; Engqvist \& Reinhold 2005). Because sperm production is costly and potentially limited (Dewsbury 1982; Nakatsuru \& Kramer 1982), selection should therefore favour males who pay attention to and use information to assess the SCR associated with any given mating opportunity, and choose mates in a manner that maximizes their reproductive success (Wedell et al. 2002). Male 
can potentially gain information about their immediate SCR at a given mating opportunity using various cues depending on the species. One type of potential cue is social information (Danchin et al. 2004), such as a female seen interacting sexually with another male. In fact, several studies have shown that males adjust their mating preference after viewing their initially-preferred female with one or more rival males (Schwagmeyer \& Parker 1990; White \& Galef 1999; Dosen \& Montgomerie 2004b; Wong \& McCarthy 2009), as would be predicted by sperm competition theory (Parker 1970; Simmons 2001; Engqvist \& Reinhold 2005). In some species, full interaction between a female and a rival male is required to serve as a reliable cue of SCR (White \& Galef 1999; Dosen \& Montgomerie 2004b), whereas only the presence of a rival male near the initially-preferred female is sufficient to indicate a risk of sperm competition in other species (Wong \& McCarthy 2009). Notwithstanding these and other studies (e.g. Smith et al. 2003), additional research is required for a more comprehensive understanding of the prevalence of use and importance of social-cue predictors of SCR on flexible male mating tactics.

Here, I investigated male mating preferences in response to socio-sexual cues as predictors of SCR using the Trinidadian guppy (Poecilia reticulata) as a model study species. I tested whether wild-caught male guppies would modify their initial mating preference for either of two stimulus females by experimentally increasing the male's apparent SCR. This was done by allowing focal males to observe either (i) a rival male placed near (but not physically interacting nor copulating with) their initially-preferred female or (ii) a rival male fully interacting with (pursuing, courting and potentially copulating with) their initially-preferred female. In the absence of a nearby rival male 
(i.e. absence of apparent local SCR), I expected that focal males would be consistent in their mating preferences between the two consecutive preference tests. However, based on sperm competition theory (Parker 1970; Simmons 2001; Engqvist \& Reinhold 2005), I predicted that focal males would modify their initial mating preference in the face of apparent SCR and prefer to associate with the female that was not recently observed in the presence of, or sexually interacting, with a rival male. I further predicted that the magnitude of any SCR-mediated shift in mating preference would be greater in the second experimental treatment above (copulation by rival male possible), which I assumed would represent a more elevated SCR, than in the first treatment (copulation by rival male not possible).

The guppy is an internally-fertilizing poeciliid fish that exhibits a non-resourcebased, promiscuous mating system in which females mate with numerous males during their lifetimes and apparently only receive sperm from them (Houde 1997). Males and females co-occur in mixed-sex shoals in nature, wherein males typically encounter multiple females concurrently (Houde 1997) and spend most of their time pursuing females (Magurran \& Seghers 1994). As a result, females can receive up to one male mating attempt per minute (Magurran \& Seghers 1994). Males attempt matings with females using two alternative tactics (Houde 1997), namely cooperative mating using courtship behaviour (sigmoid displays, usually successful only with receptive or virgin females), or coerced copulation (sneak gonopodial thrusting, typically directed at unreceptive females). Both mating tactics can result in the transfer of sperm into the gonoduct of females (Pilastro \& Bisazza 1999; Matthews \& Magurran 2000; Evans et al. 2003a) and females can store viable sperm for up to six months (Houde 1997). In natural 
Trinidadian populations of the guppy, large proportions of adult females have multiplysired broods (Kelly et al. 1999; Neff et al. 2008); therefore, males in natural populations of the Trinidadian guppy experience high sperm competition risk. As a consequence, they ought to be choosy in their mate choice and be sensitive to information associated with female mating status. Indeed, male guppies do not mate indiscriminately. In the laboratory, males tend to prefer the larger of available females (Dosen \& Montgomerie 2004a; Herdman et al. 2004), which are more fecund (Reznick \& Endler 1982), and can distinguish between virgin females and previously-mated ones using olfactory cues, preferring the former (Guevara-Fiore et al. 2009). To my knowledge, there is only one study to date (Dosen \& Montgomerie 2004b), using lab-born guppies descended from a Venezuelan population, that has reported evidence that male guppies are able to use social information predicting SCR (i.e. rival males interacting with a preferred female) in making mate-choice decisions. These investigators used four rival males to simulate an elevated risk of sperm competition. However, because four males pursuing a single female may be higher than what a male would usually observe in nature (see Results section below), it remains unknown whether the number of males who simultaneously pursue a female in the wild is able to influence a male guppy's mate choice. For this reason, I first performed field observations to determine how many male guppies pursue a single female in nature and used this number to simulate an elevated SCR in my laboratory mate choice trials. 


\section{METHODS}

\section{Study Population}

The current study was conducted on wild guppies from the Quaré River, Trinidad, West

Indies (10 $\left.41^{\prime} 25^{\prime \prime} \mathrm{N}, 61^{\circ} 11^{\prime} 51^{\prime \prime} \mathrm{W}\right)$. This population has a female-biased sex ratio (Godin 1995), adult females vary widely in body size and fecundity (Kelly et al. 1999; Herdman et al. 2004), and most (60 - 100\%) adult females have broods that are multiply-sired, with the number of sires per brood ranging from 1 to 9 (Kelly et al. 1999; Neff et al. 2008). Therefore, males in this population experience high levels of SCR.

\section{Field Observations}

I carried out visual focal observations (Martin \& Bateson 1986) of free-ranging females in the Quaré River to determine the number of males simultaneously sexually pursuing individual females. At each of eight locations (small pools) along two sections $(280 \mathrm{~m}$ and $210 \mathrm{~m}$ in length, respectively) of the river $1.2 \mathrm{~km}$ apart, I delineated an "arena" $(\sim 1$ $\mathrm{m}^{2}$ quadrat) using natural landmarks on the substratum and observed focal female guppies as they entered the arena. A focal female was continuously observed once she entered the arena and the number of males in pursuit was recorded until she exited the arena or was lost from sight. Observations were made between 08:30 - 15:00 hrs over five days between 4 May and 1 June 2009. Since the observed fish were not marked individually, no more than 10 females were observed in any one pool on the same day to minimize the likelihood of repeatedly observing the same females. 


\section{Mate-Choice Experiment}

\section{Subjects and Holding Conditions}

All experimental fish were collected haphazardly by hand seining from the Quaré River in May 2009, and the experiment (described below) were performed within two weeks of fish collection. The fish were held in 150-L mixed-sex aquaria filled with filtered aged tap water $\left(24-26^{\circ} \mathrm{C}\right)$ at the University of the West Indies, St. Augustine, Trinidad and fed ad libitum twice daily with commercial flake food until used in the experiment. Males from one holding aquarium were always tested with unfamiliar females taken from a different holding aquarium. The guppies were returned to the Quaré River at the end of the study.

\section{Experimental Apparatus}

The experimental apparatus consisted of a test aquarium (40 x $20 \times 25 \mathrm{~cm}$; L x W x H), flanked by a clear Plexiglas container $(15 \times 20 \times 22 \mathrm{~cm})$ at either end (Fig. 3.1). The central aquarium served as the mate-choice arena and held the focal male. Vertical lines drawn on the front and back walls of the test aquarium demarcated a 10-cm wide male mating preference zone near each of the end compartments. The two end compartments held the stimulus fish (female alone or female and rival male, depending on the treatment). Each compartment could be either divided in half by a clear Plexiglas partition or left undivided. The focal test male in the test aquarium therefore had access to only visual cues from both the stimulus females, and any rival male, in the end compartments. 


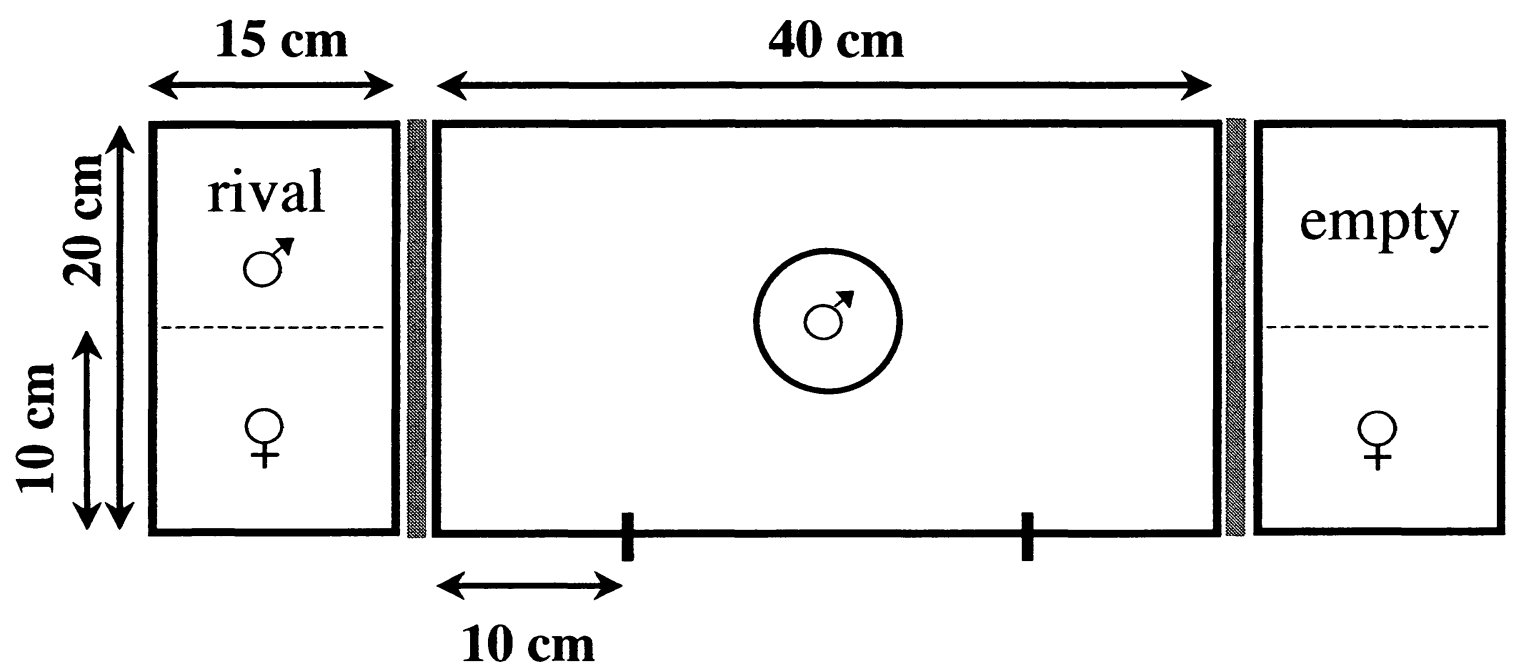

Figure 3.1. Schematic top view of the experimental apparatus. The central aquarium held the focal male and each the two end compartments held a stimulus female and, depending on the treatment, a rival male or not. The circle represents a removable clear Plexiglas tube, in which the focal male could be temporarily placed. The dashed lines represent removable clear Plexiglas partitions that allowed the end compartments to either be open or divided in half, the shaded lines denote removable opaque screens, and the "tick" marks on one side of the central aquarium denote the limits of the $10-\mathrm{cm}$ wide preference zones. 
The bottom of the test aquarium and end compartments were covered with a layer of small gravel collected from the Quaré River. The back wall of the aquarium and three sides of the stimulus compartments were covered internally with brown plastic corrugated board to provide a uniform visual background and reduce external disturbances. The test aquarium and end compartments were filled with aerated aged water $\left(15 \mathrm{~cm}\right.$ depth, $\left.24-26^{\circ} \mathrm{C}\right)$. A blind was placed in front of the central compartment, and the focal male behaviour was observed from behind the blind through an horizontal slit covered with black mesh screen.

\section{General Experimental Protocol}

The following general protocol is common to all three treatments described below. Any given behavioural trial consisted sequentially of an acclimatization period, an initial mating preference test (Preference Test 1), and a second mating preference test under a simulated risk of sperm competition (Preference Test 2). Therefore, each focal male was tested twice for his mating preference and thus acted as his own control.

The day before being used in a trial, males were temporarily isolated into an allmale holding aquarium. This period of isolation from females allowed the males time to replenish their sperm reserves and ensured that all males were similarly sexually motivated at the onset of the behavioural trials.

On the day of a trial, the standard body lengths of all fish to be used in that trial were measured without anesthesia. A focal male was then introduced into the test aquarium and allowed to swim freely and one stimulus female was randomly placed into each of the two end compartments. The paired stimulus females were gravid and 
matched for body length ( $\leq 1 \mathrm{~mm}$ difference, using a measuring scale) and the degree of abdominal distension. All fish were left undisturbed to acclimatize for 10 min, during which time opaque screens blocked the focal male's view of the females. Following Ptacek \& Travis (1997) and Dosen \& Montgomerie (2004b), I used gravid females as stimulus fish to ensure that male mate choice would not be confounded by female responses to male sexual activity.

Following this acclimatization period, the focal male's initial mating preference was ascertained in Preference Test 1 . The focal male was gently dip-netted and placed in a clear Plexiglas tube $(7 \mathrm{~cm} \mathrm{diam}$.) in the centre of the test aquarium. The opaque screens were then removed, allowing the male to observe the stimulus females for $15 \mathrm{~min}$. Following this viewing period, the focal male was released from the Plexiglas tube and allowed to choose between the two females during a 15-min mating preference test. Following Herdman et al. (2004), the time the male spent in the preference zone adjacent to each stimulus female, and facing $\left(0 \pm 90^{\circ}\right.$ relative to the female $)$ the female, was recorded as a proxy measure of his mating preference. This criterion, or slight variants of it, for mate preference is commonly used for poeciliid fishes (Bisazza et al. 1989; Dosen \& Montgomerie 2004b; Plath et al. 2008). In a related experiment (see Chapter 2), I allowed the focal male to swim in an open arena with the two females immediately following an initial visual dichotomous-choice test. I found that association time measured in the dichotomous-choice test was positively correlated with the number of sigmoid displays $\left(r_{s}=0.56, P=0.03, N=15\right)$ and duration of pursuits $\left(r_{s}=0.57, P=\right.$ $0.002, N=26$ ) directed at the same females. 
Immediately following Preference Test 1 , the opaque screens were replaced and the focal male was placed in the central Plexiglas tube. A rival male was then placed next to the particular female that the focal male had initially preferred in Preference Test 1 , thereby simulating an elevated risk of sperm competition associated with that female relative to the other female. The focal and rival males were matched for standard body length ( $\leq 1 \mathrm{~mm}$ difference). The opaque screens were then removed and the focal male allowed to observe the stimulus females and rival male for $15 \mathrm{~min}$. Following this viewing period, the opaque screens were replaced and the rival male was removed (by dip-netting) from the end compartment of the initially-preferred female. In the end compartment of the other female (which contained no rival male), removal of a rival male was concurrently simulated with a dip-net to ensure that both females experienced similar disturbance. The opaque screens were once again removed and the focal male released from the central Plexiglas tube for a second 15-min mating preference test, as for Preference Test 1.

To control for the possibility that focal males avoided associating with stressed females, I excluded trials in which the female did not resume normal swimming in Preference Test 2. A trial was also discarded either if the focal male did not sample both preference zones in Preference Test 1, the focal male appeared stressed or unhealthy, or technical problems resulted in unequal lighting. A total of eight trials were excluded.

Using this general protocol, the following three treatments were performed. Each trial tested a different focal male $(N=67)$ and they were performed in random order. Paired stimulus females $(N=134)$ were used in only one trial and not re-used. 


\section{Treatment A: No sperm competition risk}

As a control, the general protocol (described above) was performed without a rival male present during the viewing period of Preference Test 2; that is, Preference Test 1 was simply sequentially repeated. A total of 23 trials were performed. I predicted that focal males would not reduce nor reverse their preference for their initially-preferred female, and thus their mating preferences would be consistent between the two consecutive preference tests.

\section{Treatment B: Presence of a rival male as a cue for SCR}

To determine whether focal males use the mere presence of a rival male as a cue for SCR, the initially-preferred stimulus female and rival male were separated by a clear Plexiglas partition in her end compartment (Fig. 3.1). The behaviours of the rival male and stimulus female were recorded with an overhead video camera. A total of 22 trials were performed. If the presence of a rival male near a female is a predictor of SCR, then in Preference Test 2 the focal male is expected to preferentially associate with the female that was alone during the viewing period. However, there is evidence from previous studies on Venezuelan guppies (Dosen \& Montgomerie 2004b) and Japanese quail, Coturnix japonica (White \& Galef 1999) that full interaction between a female and a rival male is required for focal male avoidance of an apparently mated female. If this is true for wild-caught Trinidadian guppies from the Quare River, then the focal male's initial mating preference should alternatively remain unchanged between the two consecutive preference tests in my Treatment B. 


\section{Treatment C: Full interaction with a rival male as a cue for SCR}

This treatment tested the preference of focal males between a female alone and a female recently seen fully interacting with a rival male. In the viewing period of Preference Test 2 , the rival male had full interaction with the initially-preferred stimulus female in her end compartment. The behaviours of the rival male and stimulus female were recorded with an overhead video camera. A total of 22 trials were performed. If a focal male uses the observation of a rival male interacting or copulating with a female as a predictor of $\mathrm{SCR}$, then the focal male is expected to preferentially associate with the unmated female in Preference Test 2. That is, if a focal male shows a preference for a specific female in Preference Test 1, then this preference should be reduced or reversed in Preference Test 2.

The magnitude of this predicted SCR-mediated shift in preference is expected to be greater than that for Treatment B (i.e. initially-preferred female near a rival male, but not physically interacting with him), assuming that the apparent SCR is higher in Treatment $\mathrm{C}$ than in Treatment $\mathrm{B}$.

\section{Fish body size and male coloration}

There was no significant difference between treatments in the body lengths of focal males (one-way ANOVA: $F_{2,64}=0.05, P=0.95$ ), stimulus females (one-way ANOVA: $F_{2,131}=$ $1.25, P=0.29$ ), or rival males (independent $t$-test: $t_{42}=0.31, P=0.76$ ). For all three treatments collectively, the average ( $\pm S E$, range) standard length of the focal males, stimulus females and rival males was $16.6 \mathrm{~mm}( \pm 0.12,14.7-19.7, N=67), 23.1 \mathrm{~mm}( \pm$ $0.26,17.0-32.0, N=134)$ and $16.4 \mathrm{~mm}( \pm 0.13,14.6-18.1, N=44)$, respectively. 
At the end of each trial, the focal and rival males were anaesthetized with MS-222 and their left side photographed next to a ruler using a digital camera to quantify their body coloration patterns. In the guppy, male sexual ornamentation (body coloration) is correlated with sperm quality (Locatello et al. 2006), and the sperm of relatively colourful males are more successful in sperm competition (Evans et al. 2003b). The areas of black and orange pigmentation on the left side of each male's body, excluding the fins, were separately quantified from their photos using Image $J$ software. Relative area of total body colour ([Black Area + Orange Area]/Total Body Area) was calculated for each male. A trained observer who was blind to the experiment analyzed all photos.

\section{Statistical Analyses}

I report descriptive statistics as means $( \pm S E$, range, $N)$. Data were tested for normality using the Kolmogorov-Smirnov and Shapiro-Wilks tests. I calculated the proportion of time focal males spent associating with the initially preferred female in the paired Preference Test 1 and Preference Test 2. These data were not normally distributed, even after performing arcsine transformations; therefore, I compared Preference Test 1 and Preference Test 2 data using the Wilcoxon signed rank test (two-tailed) for each of the three treatments separately. To compare across all three treatments, I calculated for each male a difference score for any change in mating preference between the matched preference tests [Difference Score $(\%)=$ Proportion of time near initially-preferred female in Preference Test $2(\%)$ - Proportion of time near initially-preferred female in Preference Test $1(\%)$ ]. A negative value indicates a decrease in the proportion of time a focal male spent with the initially-preferred female. The data were not normally 
distributed, and therefore I used a Kruskal-Wallis $\mathrm{H}$ test to analyze them. I also compared the three treatments using the number of focal males that reversed their initial preference in Preference Test 2 in each treatment. Preference for a particular female was defined as a male spending more than $50 \%$ of his time associating with her. I compared frequencies of occurrence of mate-choice reversal using the $G$-test, following Dugtakin \& Godin (1992).

\section{RESULTS}

\section{Field Observations}

I observed 86 free-ranging focal females in the Quaré River, for an average of $88.6 \pm 7.0$ s each (range $=15-331 \mathrm{~s}$ ). Females were observed with or without a male in pursuit, and the same female often experienced both situations during a focal observation period. In total, 194 sexual pursuits were observed, with the majority $(N=158$, or $81.4 \%$ of cases) involving one pursuing male. The maximum number of males observed simultaneously pursuing a female was two $(N=36$, or $18.6 \%$ of cases $)$.

\section{Mate-Choice Experiment}

The mean proportion of time spent with the initially-preferred female in Preference Test 1 was $73.8 \%( \pm 1.85,51.25-99.76, N=67)$. There was no significant difference between treatments (Kruskal-Wallis H test: $\chi_{2}^{2}=3.25, P=0.20, N=67$ ).

As predicted, males were consistent between the two consecutive preference tests in their choice of female when no rival male was present (Wilcoxon test: $Z=-0.018, P=$ 
0.86, $N=23$; Fig. 3.2a). Focal males significantly reduced the time spent near their initially-preferred female after having observed a rival male near, but not physically interacting with, her (Wilcoxon test: $Z=-3.23, P=0.001, N=22$; Fig. 3.2a) and also after having observed their initially-preferred female interacting with a rival male (Wilcoxon test: $Z=-2.289, P=0.02, N=22$; Fig. $3.2 \mathrm{a}$ ), as expected.

There was no significant difference in the difference preference score across treatments (Kruskal-Wallis $\mathrm{H}$ test: $\chi_{2}{ }_{2}=5.53, P=0.06, N=67$; Fig. 3.2b). This result was only slightly above the threshold for significance. However, the frequency of males reversing their initial mating preference between the two consecutive preference tests differed significantly between treatments ( $G$-test; $G_{2}=13.374, P=0.001$; Fig. $\left.3.2 \mathrm{c}\right)$. Post-hoc $2 \times 2$ comparisons revealed that significantly more males reversed their preference in Treatment B compared to Treatment $\mathrm{A}\left(G_{l}=13.014, P=0.001\right.$; Fig. $\left.3.2 \mathrm{c}\right)$ and significantly more males reversed their preference in Treatment $\mathrm{C}$ compared to Treatment $\mathrm{A}\left(G_{l}=5.976, P=0.02 ;\right.$ Fig. $\left.3.2 \mathrm{c}\right)$. However, contrary to expectations, there was no significant difference in choice reversal frequencies between Treatment B and Treatment C $\left(G_{1}=1.475, P=0.23\right.$; Fig. $\left.3.2 \mathrm{c}\right)$.

\section{Male Coloration}

The percentage of the body covered by black and orange pigmentation for focal males $(10.2 \pm 0.5 \%, 3.2-24.9 \%, N=67)$ and rival males $(9.1 \pm 0.6 \%, 3.4-20.8 \%, N=44)$ did not differ between treatments (focal males: one-way ANOVA, $F_{2,64}=2.227, P=0.12$; rival males: independent $t$-test, $t_{81}=1.004, P=0.32$, two-tailed). So the apparent 

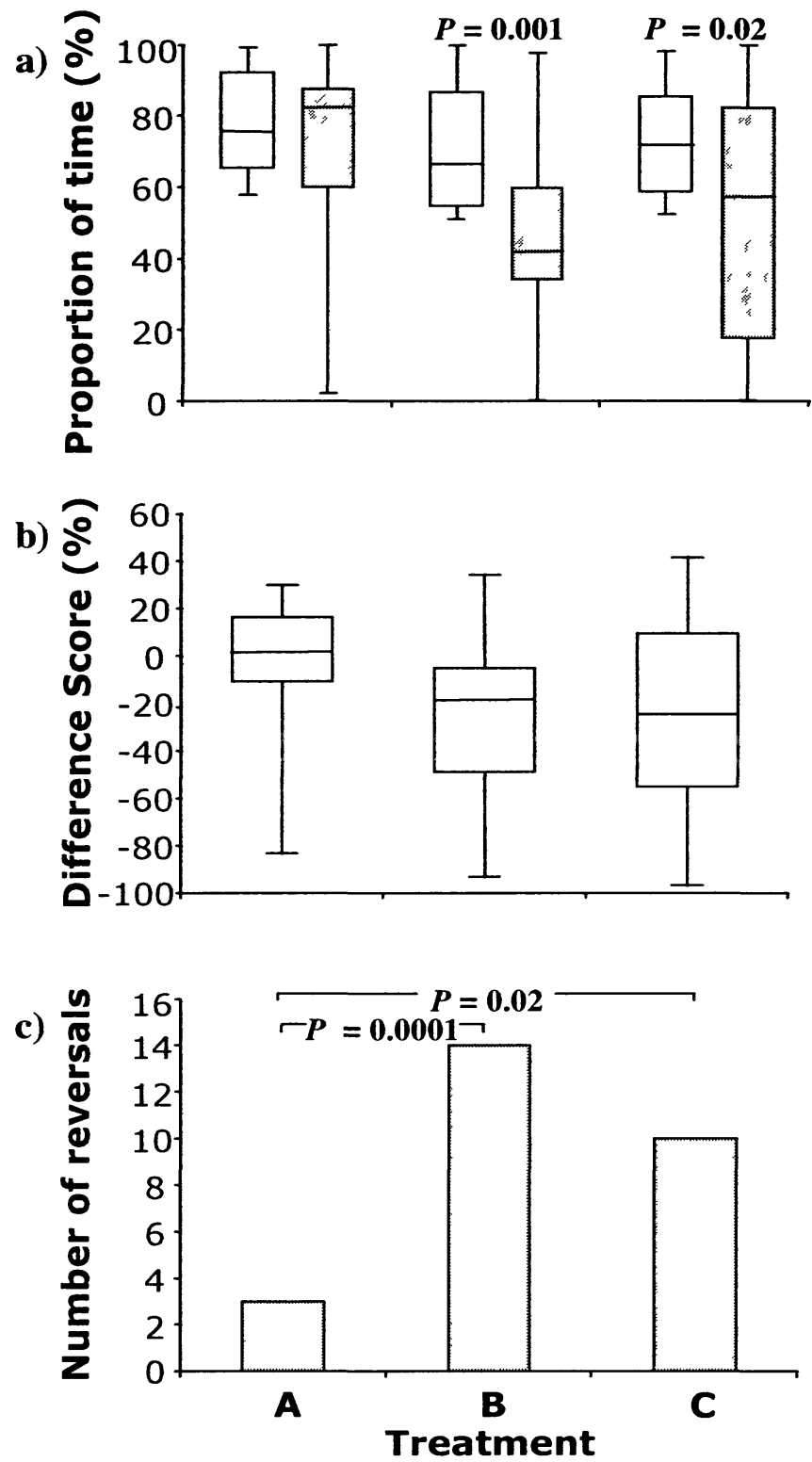

Figure 3.2. Mating preferences of focal males after observing the female preferred in Preference Test 1 either in the absence of any rival male nearby (Treatment A), in the presence of a rival male behind a clear partition (Treatment B), or fully interacting with a rival male (Treatment $C$ ). Preference is presented using three measures: (a) time focal males spent associating with the female preferred in Preference Test 1 (open bars: Preference Test 1, shaded bars: Preference Test 2); (b) difference score between Preference Test 1 and Preference Test 2 (a negative value indicates a decrease in preference in Preference Test 2); (c) the number of males that reversed their initial preference in Preference Test 2. Box plots depict the twenty-fifth, fiftieth (median) and seventy-fifth percentiles, with the whiskers showing minimum and maximum values. Only significant comparisons ( $P$-values) are shown. 
"quality" of focal and rival males, as revealed by their body coloration patterns, did not vary across the three treatments.

\section{DISCUSSION}

My study is the first to show that wild-caught male guppies pay attention to socio-sexual information that might predict the risk of sperm competition when choosing mates and use such information in modifying their mate-choice behaviour in an apparently adaptive manner. As such, the degree of mating preference exhibited by individual male guppies for particular females is apparently sensitive to their perceived SCR, a cost of mate choice for males in general (Parker 1970; Simmons 2001; Engqvist \& Reinhold 2005). I found that male guppies were choosy and consistent in the relative amount of time spent with the initially-preferred female in the absence of any rival male associating with her (i.e. in the absence of any socio-sexual cues of SCR), as expected. In contrast, when focal males could observe a rival male either fully interacting with the initially-preferred female (Treatment C) or merely present near her (but not physically interacting with her, Treatment B), they significantly reduced the magnitude of their preference for that female and, instead, spent more time associating with the other female that apparently did not represent an immediate SCR. The latter findings are as expected based on sperm competition theory (Parker 1970; Simmons 2001; Engqvist \& Reinhold 2005), and they corroborate those of White \& Galef (1999), Dosen \& Montgomerie (2004b) and Wong \& McCarthy (2009) who found that focal males decreased their tendency to associate with 
particular females after having observed them either fully interacting with or in the presence of other males.

My field observations of sexual interactions between free-ranging guppies in the Quaré River revealed that, from the vantage point of a focal male, individual females are most commonly pursued by one (rival) male. Given these observations and the facts that Quaré River female guppies experience high levels of male sneak (forced) copulation attempts (Godin 1995), high likelihood of receiving sperm by forced copulations (Evans et al. 2003a) and high rates of multiple paternity (Kelly et al. 1999; Neff et al. 2008) in the wild, male SCR in this population is very high. As a result of having evolved under high levels of SCR, Quaré River male guppies adaptively respond to an increase in apparent SCR (as perceived by local socio-sexual cues) by decreasing their tendency to associate with females that they have recently seen in the vicinity of or sexually interacting with another male. In doing so, they presumably prudently reduce their chances of mating with an already-mated female and thereby reduce their post-copulatory risk of sperm competition (cf. Wedell et al. 2002).

Interestingly, I found that focal wild-caught male guppies only had to have seen a potential rival male near (but not necessarily physically interacting with) the initiallypreferred female to subsequently reduce their mating preference for her, and that focal males seeing a rival male actually consorting with the initially-preferred female did not magnify any SCR-mediated reduction in their preference for her. These results suggest that wild male guppies from the Quaré River are sensitive to the mere proximity of one rival male to an initially-preferred female as a socio-sexual predictor of SCR and adjust their mating behaviour accordingly. This particular result is similar to that reported for 
wild-caught Eastern mosquitofish, Gambusia holbrooki (Wong \& McCarthy 2009), another livebearing poeciliid fish, but differs from one of the results of Dosen \& Montgomerie (2004b) on lab-born and raised guppies originating from a Venezualan population. Dosen and Montgomerie (2004b) reported that focal male guppies had to have previously seen rival males courting and copulating with the initially-preferred female to subsequently reduce their preference for her; the mere proximity of rival males to the female had no effect on male mating preference.

The difference between my finding and that of Dosen \& Montgomerie (2004b) may be attributable to one or more differences between the studies. First, guppy SCR in the Quaré River population is very high (as I argued above) and may be significantly greater than that in Dosen \& Montgomerie's (2004b) Venezuelan source population. Consequently, Quaré River males may be relatively more sensitive to the mere proximity of other males to an initially-preferred female, which could signal that a sneak copulation has recently occurred or is about to occur (cf. Wong \& McCarthy 2009). Second, recently-caught and tested wild guppies (the current study) might respond differently to a simulated increase in SCR than lab-born and raised guppies that are several generations removed from the wild (Dosen \& Montgomerie's (2004b) study). Third, to simulate an increase in SCR, Dosen \& Montgomerie (2004b) placed four rival males near the initially-preferred female, whereas I used only one rival male to do so. I argue that having placed one rival male near the initially-preferred female in my study more closely approximated natural conditions, as observed in the Quaré River (see Results).

A considerable body of knowledge now exists describing how males adjust their reproductive investment, in particular sperm, under the risk and intensity of sperm 
competition (reviewed in Simmons 2001; Engqvist \& Reinhold 2005). However, compared with female mate choice, relatively few studies have examined the effects of pre-copulatory mating costs on male mate choice (e.g. Schwagmeyer \& Parker 1990; White \& Galef 1999; Wong \& Jennions 2003; Dosen \& Montgomerie 2004b; Wong \& McCarthy 2009). My study contributes further to our understanding of how males respond to fluctuating costs of mating, specifically the potential cost of SCR, and thus provides behavioural support for models of sperm competition (e.g. Parker 1970, Parker et al. 1996, 1997; Simmons 2001; Engqvist \& Reinhold 2005). Wild-caught male guppies were sensitive to socio-sexual cues that might predict SCR and adjusted their mate-choice behaviour by reducing their association with initially-preferred females when they had seen those females either interacting with another male or in the vicinity of another male.

Whether male guppies similarly modify their ejaculates and(or) sperm quality when exposed to such socio-sexual cues of SCR, as predicted by theory, remains to be investigated. It is possible that they may do so, as sperm number and quality vary widely between male guppies (Pilastro \& Bisazza 1999; Evans \& Magurran 2001; Pitcher \& Evans 2001; Evans \& Rutstein 2008). Moreover, in this species, certain sperm traits, such as number, motility and length, are positively correlated with relative area of body orange coloration (Pitcher et al. 2007), and sperm number is positively correlated with male body size (Pitcher \& Evans 2001; Evans et al. 2002) and courtship behaviour (Matthews et al. 1997; Evans et al. 2002). Other potentially fruitful areas for future research using the guppy include whether male body coloration and size affect their behavioural responses to SCR, whether male mate choice is sensitive to sperm competition intensity (Parker et al. 1996) as it is to SCR, and whether males use multiple 
cues of female quality (cf. Candolin 2003) that might trade-off against SCR when assessing female attractiveness. The latter two research questions are currently being investigated in our laboratory. 


\section{CHAPTER 4}

MALE MATE CHOICE IN RELATION TO SPERM COMPETITION AND

FEMALE QUALITY IN THE TRINIDADIAN GUPPY 


\begin{abstract}
Theory predicts that males should be choosy when females vary in quality, but some measures of female quality may trade-off against each other. Here, I explored the effects of sperm competition and female body size (as a proxy measure of fecundity) on male mating decisions. I tested whether males would modify their initial mating preference for a particular female by experimentally manipulating the apparent immediate risk (SCR) and intensity (SCI) of sperm competition. To test whether fecundity trades off against sperm competition, I used female body length as a predictor of fecundity and manipulated the relative size difference of the two stimulus females (matched or differed considerably in body length) concurrently with the apparent SCR/SCI. When all else was equal, males preferred the larger female when the paired females differed considerably in body length. In the absence of rival males, focal males consistently preferred the same female, whether the females were similar or considerably different in body length. The presence of one or two rival males significantly decreased the duration of time a male spent associating with his initially-preferred female, but the effect of one rival male was not significantly different from that with two rival males. Males were also more likely to reverse their preference after observing their initially-preferred female with one rival male when the females were similar in body length than when they differed considerably in body length. These results suggest that male guppy mating behaviour is sensitive to socio-sexual cues predicting SCR, but not SCI. Males also appear to simultaneously evaluate SCR and female fecundity, and accept the potential cost of sperm competition in order to mate with a larger, more fecund female.
\end{abstract}




\section{INTRODUCTION}

In Chapter 3, I showed that wild male Trinidadian guppies were able to discriminate berween females as potential mates based on socio-sexual information that may predict the risk of sperm competition (SCR). These findings support sperm competition theory (Parker 1970; Simmons 2001; Engqvist \& Reinhold 2005) and corroborate previous studies that found males avoided females whom they had previously observed with rival males (Schwagmeyer \& Parker 1990; White \& Galef 1999; Dosen \& Montgomerie 2004b; Wong \& McCarthy 2009). There are still, however, several aspects of male mate choice in relation to sperm competition that are not well understood. For example, theory predicts that, in addition to SCR, males should also be sensitive to sperm competition intensity (SCI) (Parker et al. 1996), but it is unknown whether male mating decisions are shaped by SCI. It is also unknown whether males are able to simultaneously assess sperm competition and other cues of female quality, and how such an assessment might affect male mate-choice behaviour. For instance, the same female may be associated with a high SCR/SCI, but also high fecundity. In this case, it is possible that the benefit of mating with a fecund female outweighs the cost of sperm competition (Reinhold et al. 2002). Here, I addressed these two questions using wild-caught male Trinidadian guppies from the same population used in my previous experiments (Chapters 2 and 3 ).

SCR is the probability that a focal male's sperm will compete against the sperm from other males for a given set of ova, whereas $\mathrm{SCI}$ refers to the number of competing ejaculates (Parker et al. 1996). Males are often able to tailor their ejaculate size, and there has been much research into how males allocate sperm in response to sperm competition (Wedell et al. 2002). Theory predicts that sperm expenditure should increase 
with SCR (Parker et al. 1997), but should then decrease as the number of competitors increases above one (Parker et al. 1996). Empirical data from several taxa support these predictions (Wedell et al. 2002), and there is evidence that males will forego mating completely if the SCI is too high (Fuller 1998). This suggests that, in addition to SCR, male mate-choice behaviour may also be influenced by SCI. One potential cue for SCI that a male guppy could encounter in nature is social information (Danchin et al. 2004; Evans 2009), such as the number of (rival) males interacting with a female.

In addition to SCR and SCI, males may be able to assess other measures of female attractiveness that trade off against the cost of sperm competition. For example, a female's egg content may affect how males respond to perceived sperm competition (Galvani \& Johnstone 1998; Reinhold et al. 2002). A male's reproductive success can be increased by mating with a female with more eggs and, as a result, males often prefer to mate with more fecund females (Andersson 1994). Males of several species also invest more energy prior to or during mating with a larger female, such as presenting them with larger nuptial gifts (Engqvist \& Sauer 2001), taking part in more aggressive interactions with other males while accompanying them (Ancona et al. 2010), or transferring more sperm during mating (e.g. Shapiro et al. 1994; Gage \& Barnard 1996; Gage 1998; Parker et al. 1999; Wedell \& Cook 1999). As a result, larger, more fecund females can have more mates than smaller, less fecund ones (e.g. Herdman et al. 2004). Collectively, these findings suggest a greater SCR is associated with more fecund females. However, even though more fecund females tend to receive more sperm on average than less fecund females, they could still have a higher ratio of fertilizable eggs to sperm in their reproductive tract (Reinhold et al. 2002). In this case, a male may still benefit from 
mating with a more fecund, mated female compared to a less fecund, unmated female. However, as the ratio of eggs to sperm in a female's reproductive tract decreases, this advantage could be lost. Therefore, if a male can simultaneously assess a female's current fecundity and the local SCR and SCI, his mate-choice decision ought to reflect a balance between these correlates of female quality or attractiveness.

Here, I investigated the simultaneous potential effects of sperm competition and female fecundity on male mate-choice behaviour in the Trinidadian guppy by concurrently manipulating the relative fecundity of females and the perceived SCR/SCI. This was done by (i) presenting individual focal males with a choice between two females that were either matched as closely as possible in body length or different in body length by approximately $25 \%$, and (ii) then allowing the focal male to observe his initially-preferred female interacting with either zero, one or two rival males. In the guppy, female fecundity is strongly correlated with body length (Reznick \& Endler 1982; Reznick 1983). I predicted that, when females are similar in body length (fecundity), the focal males would be consistent in their mate choice in the absence of rival males, but that focal males would decrease the amount of time they spent with their initiallypreferred female after observing her with one or two rival males. Furthermore, I expected that the magnitude of this reduction in preference would be greater for two rival males compared to one rival male. When females differed in body length and males initially preferred the larger female, I also expected that focal males would be consistent in their mate choice in the absence of rival males. However, because the benefit of mating with a female with more eggs may outweigh the cost of sperm competition (Reinhold et al. 2002), I predicted males would be consistent in their mate choice after 
observing the larger female with one rival male. This benefit may be lost as SCI increases; therefore, I expected focal males to decrease the amount of time associating with the larger female after observing her with two rival males.

The Trinidadian guppy is an appropriate model organism for studying male mate choice in relation to SCR, SCI and female fecundity. In the wild, female guppies vary in the number of males with which they mate (Kelly et al. 1999; Becher \& Magurran 2004; Herdman et al. 2004; Neff et al. 2008) and also in the number of males sexually-pursuing them (see Chapter 3). Therefore, males may be able to use socio-sexual cues (such as the number of rival males pursuing a female) to assess SCI and respond accordingly. Guppies are also useful for investigating whether males simultaneously assess female fecundity and sperm competition during mating decisions. Females vary widely in fecundity and males are likely able to assess this variation using female body size, which is positively correlated with fecundity (Reznick \& Endler 1982; Reznick 1983). Indeed, previous studies have found that male guppies prefer larger females as mates (Dosen \& Montgomerie 2004a; Herdman et al. 2004). It remains unknown, however, whether males are able to simultaneously assess female fecundity, SCR and SCI and adjust their mating decisions in a manner that maximizes their reproductive success.

\section{METHODS}

\section{Subjects and Holding Conditions}

The current study was conducted on wild-caught guppies from the Quaré River, Trinidad, West Indies $\left(10^{\circ} 41^{\prime} 25^{\prime \prime} \mathrm{N}, 61^{\circ} 11^{\prime} 51^{\prime \prime} \mathrm{W}\right)$. This population has a female-biased sex ratio 
(Godin 1995), adult females vary widely in body size and fecundity (Kelly et al. 1999;

Herdman et al. 2004), and most (60 - 100\%) adult females have broods that are multiplysired, with the number of sires per brood ranging from 1 to 9 (Kelly et al. 1999; Neff et al. 2008). Therefore, males in this population experience high levels of SCR and SCI. Fish used in this study were collected haphazardly by hand seining from the Quaré River in May 2009 and May 2010. All trials were performed within one month of collection.

The fish were held in 150-L and 75-L mixed-sex aquaria filled with filtered aged tap water $\left(24-26^{\circ} \mathrm{C}\right)$ at the University of the West Indies, St. Augustine, Trinidad and fed ad libitum twice daily with commercial flake food and live brine shrimp (Artemia sp.) until they were used in the experiment (see below). Because social familiarity can potentially affect mate choice in the guppy (Hughes et al. 1999; Kelley et al. 1999; Zajitschek et al. 2006), males from one holding aquarium were always tested with unfamiliar females taken from a different holding aquarium.

\section{Experimental Apparatus}

Male mating preference was determined using the dichotomous-choice method (see Chapter 2). The experimental apparatus was the same as the one used in my previous experiments (see Chapters 2 and 3). Briefly, it consisted of a test aquarium (40 x $20 \times 25$ $\mathrm{cm} ; \mathrm{L} \times \mathrm{W} \times \mathrm{H})$, flanked by a clear Plexiglas container $(15 \times 20 \times 22 \mathrm{~cm})$ at either end (Figs. 2.1 and 3.1). The central aquarium held the focal male, and vertical lines drawn on the front and back walls demarcated a $10-\mathrm{cm}$ wide male mating preference zone near each of the end compartments. The two end compartments held the stimulus fish (females and one or two rival males, depending on the treatment) and were always left 
undivided so that the rival male(s) could freely interact with the female. The focal male in the central test aquarium therefore had access to only visual cues from both the stimulus females and any rival male in the end compartments.

\section{General Experimental Protocol}

The day before a trial males were isolated into all-male pools and small $(17-22 \mathrm{~mm})$ and large $(23-30 \mathrm{~mm})$ stimulus females were placed into separate holding aquaria without males.

As the general protocol for testing male mate preference was identical to that used in my previous experiment (Chapter 3), I will only describe it briefly here. For a more detailed description of this protocol, see Chapter 3. Each trial consisted sequentially of a 10-min acclimation period, an initial preference test (Preference Test 1) followed immediately by a second preference test in which an elevated SCR or SCI was simulated (Preference Test 2). Therefore, each focal male was tested twice for his mating preference and thus acted as his own control. In each preference test, the focal male was allowed to view the stimulus females in their respective end compartments for $15 \mathrm{~min}$, followed by a 15-min dichotomous-choice test during which his mating preference was recorded as the amount of time he spent in the preference zone adjacent to each stimulus female, and facing $\left(0 \pm 90^{\circ}\right)$ the female. In Chapter 2 , I validated such mate-association time as an appropriate proxy measure of male mate choice in the guppy. During the viewing period of Preference Test 2, zero, one or two rival males (see below for details) were placed next to the particular female that the focal male had preferred in Preference 
Test 1 , thereby simulating an elevated SCR/SCI associated with that female relative to the other female.

The focal and rival males were matched for standard body length $(\leq 1-\mathrm{mm}$ difference) and the stimulus females were always matched for reproductive status, but were either matched for body length ( $\leq 1-\mathrm{mm}$ difference) or differed in body length by approximately $25 \%$ (see below). Female reproductive state here was assessed by visually estimating the extent of the female's abdominal distention or gravidity (cf. Houde 1997).

A trial was discarded either if the focal male did not sample both preference zones in Preference Test 1, one of the stimulus females did not resume normal swimming, or the focal male appeared stressed or unhealthy. A total of 27 trials were excluded.

\section{Experimental Treatments}

Using the general protocol described above, I performed a factorial experiment consisting of two factors, which were the apparent level of SCI (three levels) and the relative size (fecundity) of the two stimulus females (two levels). Each combination of these two factors was replicated and trials were carried out in random order. To titrate the apparent intensity of simulated sperm competition, the focal male was allowed to view his previously-preferred female with either no rival males, one rival male, or two rival males sexually interacting with her. These rival male numbers were chosen to correspond to the number of male guppies observed simultaneously pursuing a freeranging female in the Quaré River in May and June 2009 (see Chapter 3). To titrate the relative size (fecundity) of the two stimulus females, individual males were given a choice between two females that were matched as closely as possible for body length ( $\leq$ 
1 -mm difference) or different in body length by approximately $25 \%$ on average (range $=$ $4.5-6.5 \mathrm{~mm}$ difference, $N=95$ female pairs). All paired females were matched for abdominal distension.

Each trial tested a different focal male (total $N=161$ ) and stimulus females (total $N=322$ ) were not re-used. Twenty-nine of the 95 males tested in the treatments with females that differed considerably in body length preferred the smaller of the paired stimulus females in Preference Test 1 . These trials were included in the analysis testing whether or not male guppies prefer larger females in general, but were not used to test for an effect of sperm competition on male mate choice. These trials were not included for the latter analysis because the objective of the current study was to test whether the benefit of mating with a larger female outweighs the cost of sperm competition. After these trials were removed there was a total of 22 trials in each treatment (total $N=132$ ).

If males are sensitive to SCI, then the time focal males spend with their initiallypreferred females should progressively decrease as the number of rival males increases. However, if males can simultaneously assess female fecundity and the potential sperm competition risk/intensity, then the benefit of mating with a larger female may outweigh the cost of sperm competition when females differ considerably in size. As a result male preference for the larger female should be maintained after the focal male views her interacting with another male. Males may reduce their mating preference after viewing the larger female with two males, as this may indicate a higher SCI. 


\section{Male Coloration and Fish Body Size}

At the end of each trial, the focal and rival males were anaesthetized with MS-222 and their left side photographed with a ruler using a digital camera to quantify their body coloration patterns. A photograph of one of the focal males (treatment: zero rival males, females matched in body length) was missing and therefore could not be quantified. The areas of black and orange pigmentation on the left side of each male's body, excluding the fins, were separately quantified from their photos using Image $J$ software. Relative area of total body colour ([Black Area + Orange Area]/Total Body Area) was calculated for each male. There was no significant difference between treatments in the relative area of total body colour of focal males (one-way ANOVA: $F_{5,154}=0.846, P=0.52$ ) or rival males $\left(F_{3,128}=1.349, P=0.26\right)$. For all six treatments collectively, the average $( \pm$ $S E$, range) relative area of total body colour of the focal males and rival males was $9.1 \%$ $( \pm 0.30,1.3-24.0, N=160)$ and $7.2 \%( \pm 0.28,0.4-17.1, N=132)$, respectively.

There was no significant difference between treatments in the body lengths of focal males (one-way ANOVA: $F_{5,155}=0.461, P=0.81$ ), rival males $\left(F_{3,128}=1.020, P=\right.$ $0.39)$, or stimulus females $\left(F_{5,316}=0.948, P=0.45\right)$. For all six treatments collectively, the average ( $\pm S E$, range) standard length of the focal males, rival males and stimulus females was $16.8 \mathrm{~mm}( \pm 0.09,14.1-20.0, N=161), 16.5 \mathrm{~mm}( \pm 0.08,14.4-19.9, N=$ $132)$ and $22.3 \mathrm{~mm}( \pm 0.17,17.0-30.0, N=322)$, respectively.

\section{Statistical Analyses}

I report all descriptive statistics as the mean $( \pm S E$, range, $N)$. Instead of using absolute time, I calculated mean difference scores as a measure of male mating preference for 
either large or small females (see below for the calculations). All of the data met the assumptions of normality, and therefore I used parametric statistical tests.

To determine whether males prefer larger females overall, I analyzed the data from Preference Test 1, in which rival males were not present. Difference scores were calculated for Preference Test 1 of each trial as [Difference Score $=$ Association time (seconds) with the larger female - Association time (seconds) with the smaller female]. Positive values indicate that the focal male spent more time associating with the larger of the paired stimulus females. I combined separately the data from all three treatments in which the females were similar in body length $(\leq 1-\mathrm{mm}$ difference), and the data from the three treatments in which the females differed more considerably in body length. Using the independent $t$-test, I then separately compared the mean difference score for each of the above treatment groups against no preference (i.e. null difference score $=0$ ). I similarly compared the mean difference scores for these treatment groups with each other. In treatments with females matched in body length, 16 of the paired females were excluded from this analysis because they were exactly of the same size. The degrees of freedom were adjusted for unequal variances between treatments.

To test for effects of sperm competition and female size on male mate choice, I calculated male mating preference for each trial as a difference score [Difference Score $=$ Association time in Preference Test 2 with the initially-preferred female - Association time in Preference Test 1 with the initially-preferred female] and then calculated a mean difference score for each treatment separately. Negative values indicate a decrease in the time the focal male spent with the initially-preferred female in the second preference test relative to the first test. I then performed a two-way ANOVA on the difference scores to 
test for the effects of increasing both the number of rival males $(0,1$ or 2$)$ and the relative potential fecundity of the paired females (similar in length or different in length), and also whether there was an interaction between these two main effects. Post-hoc multiple comparisons of means were performed using the Tukey test when a main effect was significant. Post-hoc estimates of statistical power were calculated using the statistical software $\mathrm{G}^{*}$ Power 3 (Erdfelder et al. 1996).

\section{RESULTS}

\section{Male mating preferences and female size}

For the treatments with paired stimulus females matched as closely as possible in body length, the overall mean difference in body length of the paired stimulus females was 0.8 $\mathrm{mm}( \pm 0.04,0.25-1.0, N=50)$. As expected when females are similar in body length and presumably quality (fecundity), males in this group did not prefer either of the paired females in Preference Test 1 (independent $t$-test comparing the mean observed difference score to a null score of $0 ; t_{49}=0.228, P=0.77$; Fig. 4.1 ).

For the treatments with paired stimulus females that differed considerable in body length, the average difference in body length was $5.6 \mathrm{~mm}( \pm 0.06,4.5-6.5, N=95)$. As expected when females differ in body size by such a magnitude, focal males significantly preferred the larger female in Preference Test 1 (independent $t$-test comparing the observed mean difference score to a null score of $0 ; t_{94}=4.404, P<0.001$; Fig. 4.1), which was significantly greater than the time males spent with the larger female when 


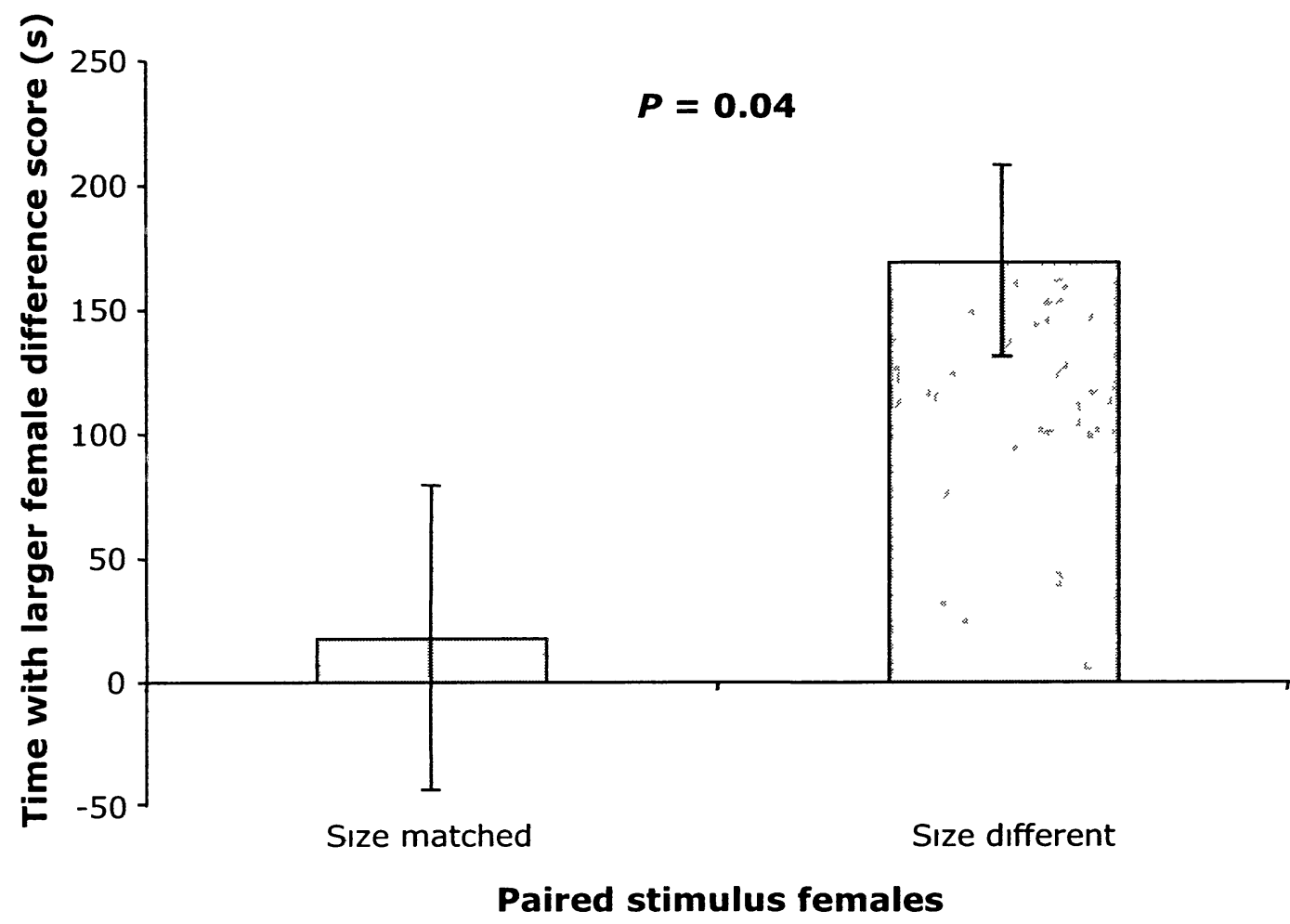

Figure 4.1. Mean $( \pm S E)$ difference score in the time focal males spent associating with the larger female in Preference Test 1. A positive value indicates the males spent more time with the larger female. The paired stimulus females were either similar $(0.8 \mathrm{~mm} \pm$ $0.04)$ or considerably different $(5.6 \mathrm{~mm} \pm 0.06)$ in body length. 
paired females were similar in body length in Experiment 1 (independent $t$-test: $t_{88}=$ 2.191, $P=0.04$; Fig. 4.1).

\section{Male mating preferences in relation to sperm competition and female size}

\section{Association time with the initially-preferred female}

Overall, apparent sperm competition, as simulated by the number of rival males near the female initially preferred by focal males, affected the latter's mate-choice behaviour (two-way ANOVA; $F_{2,126}=5.061, P=0.008$; Fig. 4.2) in the predicted direction. Posthoc Tukey multiple comparisons revealed that the amount of time focal males spent associating with their initially-preferred female declined significantly in the presence of one rival male $(P=0.04)$ and two rival males $(P=0.01)$ relative to the control treatment (no rival male present), but that the effect of one rival male was not significantly different from that of two rival males $(P=0.90)$. Therefore, male guppies significantly reduced their initial preference for a particular female after observing her interacting with either one or two rival males, but the magnitude of this reduction in mating preference was insensitive to the number of rival male present (at least up to 2).

The other main effect, that of the difference in body length of the paired stimulus females, was not significant $\left(F_{1,126}=0.304, P=0.58\right.$; Fig. 4.2$)$, nor was the interaction between the two main effects (number of rival males $\mathrm{x}$ female body-size difference; $F_{2,126}$ $=1.015, P=0.37 ; \mathrm{Fig}, 4.2)$. The latter result is not as was predicted $a$ priori; $\mathrm{I}$ had 


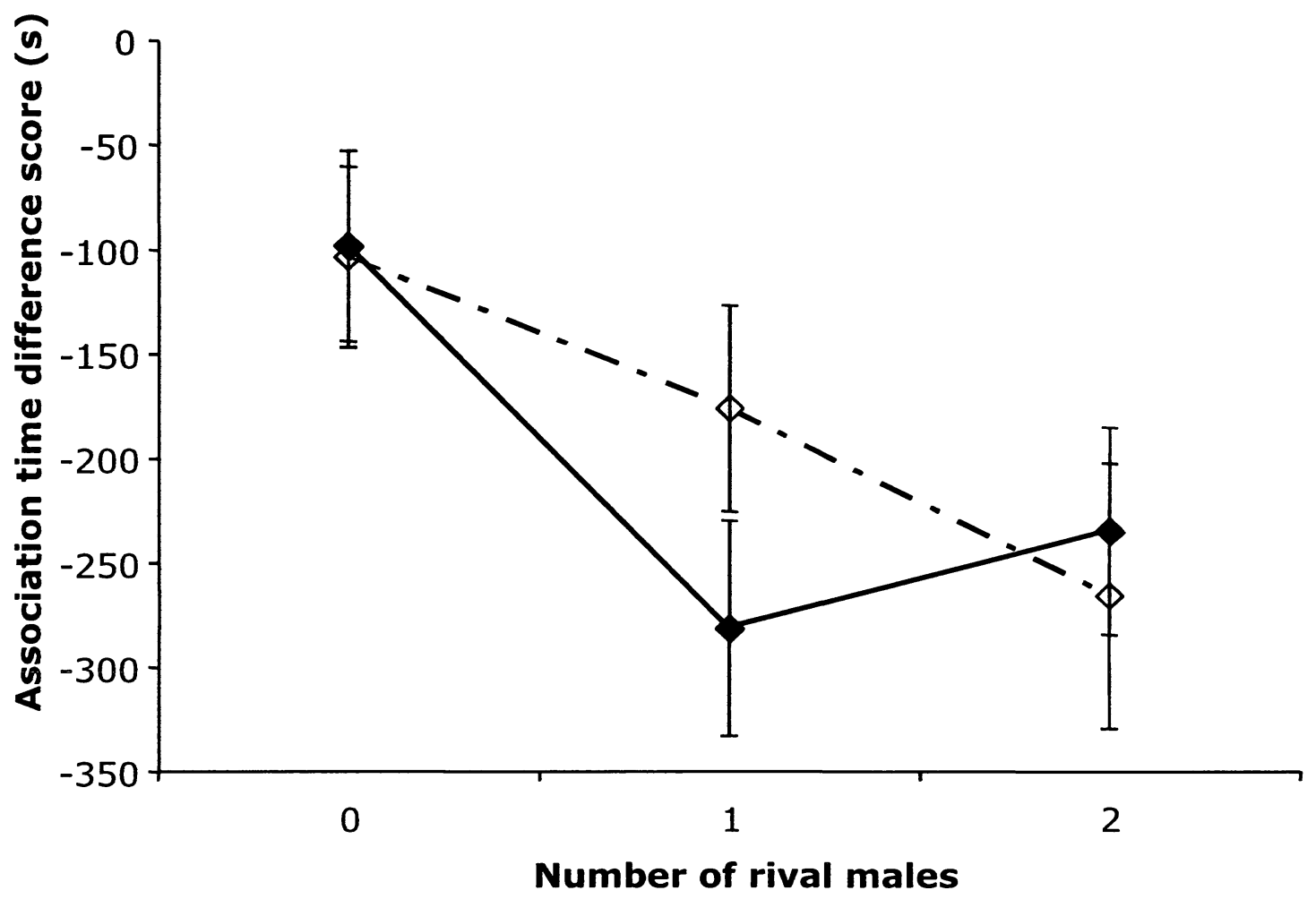

Figure 4.2. Mean $( \pm S E)$ difference score in the time focal males spent associating with the initially-preferred female after observing her interacting with either zero, one or two rival males. A negative value indicates a decrease in the amount of time. The paired stimulus females were either similar (closed symbols and solid line: mean size difference $=0.6 \mathrm{~mm} \pm 0.05$ ) or considerably different (open symbols and dashed line: mean size difference $=5.7 \mathrm{~mm} \pm 0.07$ ) in body length . 
expected that the benefit of mating with a larger, more fecund female would outweigh the potential cost of associated sperm competition, and therefore males ought to have responded differently to SCR and SCI when the paired females differed in size compared to when they were size matched. However, although the interaction term was nonsignificant, the reduction in the time focal males spent with their initially-preferred female after observing her with one rival male is smaller when the paired females differed in size compared to when they were matched for size (Fig. 4.2). An interaction cannot necessarily be ruled out because of the low power of the test (power $=0.23$; effect size $=0.13$ ) that resulted from the relatively modest sample size in individual treatments.

Therefore, for each treatment, I additionally classified the focal males' choice behaviour into two categories, consisting of whether or not individual males reversed their initial mating preference in Preference Test 2. I compared frequencies of occurrence of mate-choice reversal using the $G$-test, following Dugtakin \& Godin (1992). A focal male was classified as 'preferring' a particular female if, over the course of a preference test, his association time with that female exceeded that of the other female.

\section{Reversal of initial mating preference}

Females similar in body length

When the females were similar in body length, the results tell a similar story to those obtained using the two-way ANOVA on the continuous preference data presented above. Relative to the control treatment ( 0 rival male), a significant number of males reversed their initial mating preference after observing their initially-preferred female interact with one rival male $\left(G\right.$-test; $G_{1}=10.390, P=0.001 ;$ Fig. 4.3$)$ or with two rival males $\left(G_{1}=\right.$ 
12.338, $P<0.001$; Fig. 4.3). However, the frequencies of reversals in response to one and two rival males were similar $\left(G_{1}=0.096, P=0.76\right.$; Fig. 4.3).

\section{Females different in body length}

When paired stimulus females differed considerably in body length, however, the number of males that reversed their mating preference after observing their initially-preferred female interact with one rival male was the same as the number of males reversing their preference in the control treatment ( 0 rival male) $\left(G_{1}=0.00, P=1.0\right.$; Fig. 4.3). In addition to being identical to that of the control treatment, this number of males reversing their initial preference was also significantly lower than the number of reversals when females were similar in body length and one rival male was present $\left(G_{1}=4.627, P=\right.$ 0.03; Fig. 4.3).

More than half of the males reversed their preference after observing their initially-preferred female interact with two rival males, which was approaching significance compared to the frequency of reversals observed in the control treatment $\left(G_{l}\right.$ $=3.436, P=0.06$; Fig. 4.3 $)$ and the one rival male treatment $\left(G_{l}=3.436, P=0.06\right.$; Fig. 4.3). 


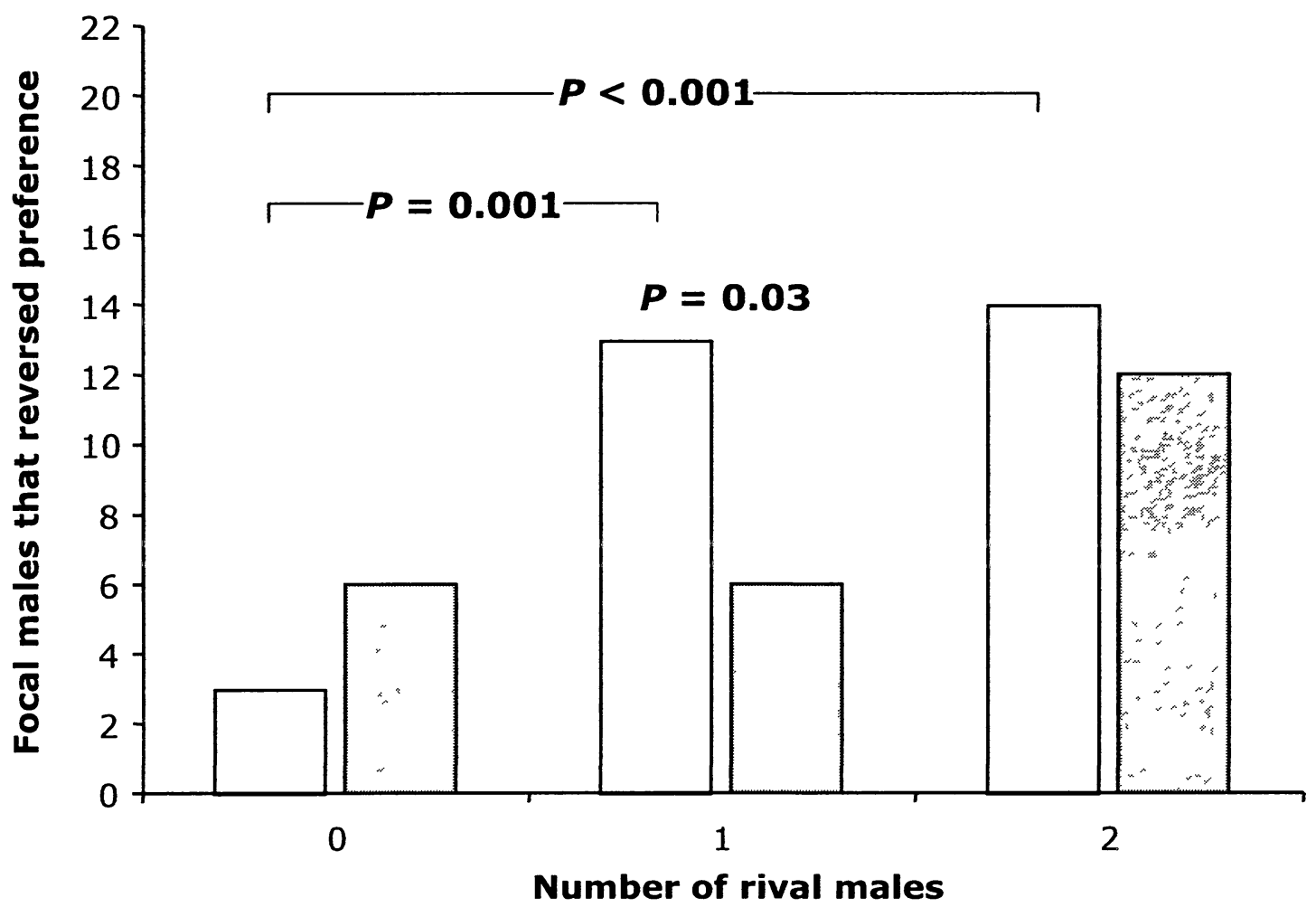

Figure 4.3. Number of focal males that reversed their initial mating preference after observing their initially-preferred female interacting with either zero, one or two rival males. The paired stimulus females were either similar (open bars, mean size difference $=$ $0.6 \mathrm{~mm} \pm 0.05$ ) or considerably different (shaded bars, mean size difference $=5.7 \mathrm{~mm} \pm$ 0.07 ) in body length. A total of 132 focal males were tested, 22 in each treatment. Only significant comparisons ( $P$-values) are shown. 


\section{DISCUSSION}

The current study demonstrated that wild-caught male Trinidadian guppies are able to differentiate between two simultaneously presented stimulus females that differed in body length by approximately $25 \%$, and preferentially associated with the larger female. When the paired females were size matched, males still showed a strong preference for one or the other female, but their preference was not related to female size. Preferring the larger female appears to be adaptive, since larger female guppies are more fecund (Reznick \& Endler 1982; Reznick 1983) and mating with a larger, more fecund female could increase the reproductive success of a male when everything else is equal (Andersson 1994). These results corroborate previous studies showing that male guppies prefer the larger female when given a choice between two females of unequal size (Dosen \& Montgomerie 2004a; Herdman et al. 2004).

In addition, the current results showed that male guppies are able to assess the apparent risk of sperm competition (SCR) associated with a particular female using socio-sexual cues, and tended to avoid females with the relatively higher apparent SCR. Consistent with the results of my previous experiment (Chapter 3), male guppies here tended to avoid associating with females they had recently observed interacting with one rival male, and instead chose to associate with the other female that they had observed alone. This result was also true for males that observed their initially-preferred female interacting with two rival males. Mating under high SCR levels can be costly for a male since it could lower the number of eggs he can potentially fertilize and thereby decrease his reproductive success (Parker et al. 1997). It would, therefore, be beneficial for a male to be sensitive to potential cues that predict SCR in order to avoid females associated 
with a higher level of SCR (Simmons 2001; Wedell et al. 2002). Females in my study population, the Quaré River, are often pursued by one or two males (see Chapter 3), which may signal to other nearby males watching this interaction that the pursued female has recently mated or is about to mate. Male guppies in this population appear to use the presence of one or two rival males in close proximity to a female as a predictor of SCR and prudently avoid these females.

Interestingly, male mate-choice behaviour did not appear to be affected by SCI. Theory predicts that as the number of competing ejaculates increases above one, a male should decrease his sperm expenditure (Parker et al. 1996; Simmons 2001; Engqvist \& Reinhold 2005). Since not mating with a female is a form of reduced sperm expenditure, I expected that the tendency for males to avoid females that they had observed interacting with rival males would be greater when the number of rival males was increased from one to two. Contrary to my expectation, the magnitude of the reduction in time that the focal males spent associating with their initially-preferred female was similar after the focal males had observed her interacting with either one or two rival males. A relevant recent study on sperm priming under increasing levels of SCI in the guppy found that there was no difference in the number or quality of the focal male's sperm after he observed a virgin female alone or with one, two or three rival males for three days (Evans 2009). Taken together, my results here and those of Evans (2009) suggest that male guppies are not sensitive to increasing immediate SCI. However, there remain a number of unanswered questions that need to be investigated before this issue can be resolved. For example, males of some fish species are able to adjust the size of their ejaculate in 
response to immediate SCI (Pilastro et al. 2002; Smith et al. 2003), but it is still unknown if guppies are capable of doing this.

An alternative explanation for my results is that male guppies are sensitive to immediate SCI, but that they do not use socio-sexual cues (i.e. rival males interacting with the female) as a reliable predictor of SCI. Having information on the number of rival males present is not necessarily the same as knowing exactly how many competing ejaculates exist, especially for internal fertilizers (Engqvist \& Reinhold 2005). When the focal male does not know the exact number of competing ejaculates, he is forced to estimate SCI. A focal male may estimate the probability of having to compete with the sperm from all of the males he recently observed with a female to be very low and, therefore, increasing the number of rival males may only increase SCR and not SCI (Engqvist \& Reinhold 2005). In my experiment, increasing the number of rival males from one to two may have represented too small of an increase in SCR to influence the focal male's mating behaviour (but see below for how males respond when female fecundity varies).

In the current study, cues that predicted SCR may have superseded those predicting female fecundity (i.e. number of potentially fertilizable eggs). There was no interaction between the two main experimental factors (number of rival males and difference in size of the paired females) on the magnitude of the decrease in time focal males spent associating with their initially-preferred female. This suggests that the focal males responded similarly to their initially-preferred female interacting with one or two rival males whether she was similar or different in body length (fecundity) to the other female. A recent theoretical model predicts that males should increase their sperm 
allocation as female fecundity increases, because the ratio of sperm to eggs is still higher in these females than in smaller, less fecund females that receive fewer sperm (Reinhold et al. 2002). In terms of mate-choice behaviour, males should therefore still choose large females over smaller ones as mates, even if larger females receive more sperm. My results may not meet this prediction because the aforementioned model assumes that mating frequency is equal for all females, which is not true for guppies. Larger female guppies often mate at a higher frequency than smaller females (Herdman et al. 2004). Moreover, if male guppies also allocate more sperm to larger females, then the benefit of mating with a larger, mated female may be lost. However, due to the low power to detect a significant interaction between the number of rival males and relative female fecundity in my study, I cannot rule out the possibility that males can concurrently assess SCR and relative female fecundity when choosing a mate.

Using an alternative measure of male mate-choice behaviour (i.e. mate-choice reversal), male guppies did appear to trade off perceived relative female fecundity against perceived SCR in their mate-choice decisions. When I categorized focal males into whether or not they reversed their initial mating preference, male response to an apparent increased in SCR appeared to be dependent on whether the paired females were similar or different in body length (fecundity). When the paired stimulus females were similar in body length, the majority of males that had viewed their initially-preferred female interact with one rival male reversed their initial mating preference. In contrast, when the females differed in body length, males tended to retain their initial preference for the larger female after viewing her with one rival male and thus were less likely to reserve their initial mating preference under such an apparent increase in SCR. However, when 
the number of rival males was increased to two, the focal males responded similarly to when the stimulus females were matched in body size, although this result was just above the significance threshold. As discussed earlier, it is unknown whether the focal males associated two rival males with a higher SCR or SCI compared to one rival male. In either case, the cost of mating with a female previously seen with two rival males may have outweighed the benefit of mating with a larger female. Therefore, it appears that male guppies in the current study concurrently evaluated female fecundity and sperm competition and accepted the potential cost of sperm competition when choosing to mate with the larger, more fecund female until the risk or intensity of sperm competition became too high.

A considerable number of studies have investigated male mating preferences for individual female qualities, such as body size (e.g. Ptacek \& Travis 1997; Kraak \& Bakker 1998), age (Muller et al. 2006), reproductive status (McLennan 1995; Deaton 2008), familiarity (Kelley et al. 1999; Zajitschek et al. 2006) and mating status (White \& Galef 1999; Dosen \& Montgomerie 2004b; Wong \& McCarthy 2009). My current study corroborates other studies reporting that male guppies prefer larger females (Dosen \& Montgomerie 2004a; Herdman et al. 2004), and also supports my previous study (Chapter 3) that found wild-caught male guppies were sensitive to socio-sexual cues of SCR and subsequently reduced their association with initially-preferred females after viewing them sexually interacting with another male. The current study also further contributes to our general understanding of the potential costs incurred by males when choosing to mate with larger, more fecund females (Engqvist \& Sauer 2001; Reinhold et al. 2002; Ancona et al. 2010) and how males respond to multiple cues of female quality (Galvani \& 
Johnstone 1998; Reinhold et al. 2002; Ojanguren \& Magurran 2004). Here, male guppies appeared to be able to simultaneously evaluate female fecundity and SCR, because they were more likely to reverse their initial mating preference after observing their initiallypreferred female interact with other males when the females were similar in body length. This particular result was only significant using categorical data (on mate-choice reversals), and therefore further research is needed to validate this finding. Another potential area of future research is the responses of males to increases in immediate SCI. In the current study, I found that increasing the number of rival males from one to two did not have a significant effect on the focal male's mate choice, but it is possible that males adjust their ejaculate size in relation to SCI or that they use a different cue that is a more reliable indicator of SCI than the number of males in close proximity to a female. Future studies should focus on these two research questions. 


\section{CHAPTER 5}

\section{GENERAL DISCUSSION}

\section{Overview of results}

Male mate choice is a growing area of research, but our current understanding of its evolution is limited. In general, there is selection for male choosiness when males experience a cost to mating that affects their ability to invest in future matings, and when females vary in quality (Dewsbury 1982; Andersson 1994; Bonduriansky 2001). Males usually discriminate between females based on a quality that affects the number of eggs they can potentially fertilize at each mating (e.g. female fecundity) rather than on indirect benefits (e.g. good genes). Since males can often assess these female qualities using visual or tactile cues, male mating preferences are more likely to reinforce natural selection than to select for elaborate female display traits (Bonduriansky 2001). The aim of my thesis was to contribute to a further understanding of factors influencing matechoice decisions in males using the Trinidadian guppy as a model study system. Although the guppy exhibits a highly promiscuous, non-resource-based mating system (Houde 1997), it is nonetheless a useful model for studying male mate choice because it meets the two criteria necessary for male mate choice to evolve. Namely, that mating is potentially costly for males (Magurran \& Seghers 1994; Godin 1995; Pilastro \& Bisazza 1999) and that females vary widely in a number of qualities, such as fecundity (Reznick \& Endler 1982; Reznick 1983), sperm competition risk (SCR) and sperm competition 
intensity (SCI) (Kelly et al. 1999; Becher \& Magurran 2004; Herdman et al. 2004; Neff et al. 2008).

In Chapter 2, I validated a laboratory-based experimental protocol, known as the dichotomous-choice test, which is commonly used to test male mate choice. Male association time with a preferred female, measured in the dichotomous-choice test, was strongly positively correlated with the amount of time a male spent sexually pursuing the same female when he was allowed to swim freely with her and the other (paired) female. Association time was also correlated with the number of sigmoid displays directed by the male at the same female. Collectively, these results are novel and demonstrate for the first time that male association time with females is a strong predictor of male sexual behaviour and mate choice when the sexes freely interact with each other. The results thus confirm that the dichotomous-choice test is an appropriate experimental method to investigate male mate choice, at least in the guppy. I therefore used this methodology in subsequent experiments, described in Chapters 3 and 4.

In Chapter 3, I tested whether males use socio-sexual information to assess the immediate SCR associated with a female and adjust their mating behaviour accordingly. To inform the design of my laboratory experiments, I first observed free-ranging adult females in the Quaré River, Trinidad to determine how many males simultaneously pursue a female in nature. The most common number of males pursuing a particular female was one and the maximum number observed was two. Therefore, in my laboratory tests, I simulated an elevated SCR using one rival male Chapter 3, and in Chapter 4 I manipulated the perceived immediate SCI using zero, one or two rival males. These simulated levels of SCR and SCI are ecologically-relevant for the Trinidadian 
guppy. In Chapter 3, as predicted by sperm competition theory (Parker 1996, 1997, Simmons 2001), I showed that male guppies significantly reduced the amount of time they spent associating with their initially-preferred female after viewing her with one rival male. Interestingly, the magnitude of this SCR-mediated response was similar when the rival male was physically separated from the female and when he was allowed to fully interact with the female. Therefore, male guppy mate choice is sensitive to SCR and males use the mere presence of a rival male as a cue for SCR.

In Chapter 4, I investigated the effect of concurrently manipulating SCI and relative female fecundity on male mate choice. As mentioned above, I titrated SCI based on the number of males I observed simultaneously pursuing a female in nature (zero, one or two). Male guppy mate choice did not appear to be sensitive to SCI, but relative female fecundity did influence a male's response to sperm competition. When females differed considerably in body size (and thus potential fecundity) and all else was equal, males tended to prefer the larger female. However, after viewing their initially-preferred female with a rival male, males were more likely to reverse their mate choice when the females were similar in size (i.e. fecundity) than when the initially-preferred female was significantly larger than the paired female. This suggests that males can simultaneously assess at least two female qualities and, in this case, female fecundity appeared to outweigh sperm competition in influencing the mate-choice decisions of males. These results are novel and importantly contribute to our further understanding of how male mating decisions are influenced by the interaction between their perceived levels of SCR/SCI and the potential fecundity of females (which is correlated with female body size in many species). 


\section{Implications and future research}

To my knowledge, my study is the first to have validated the dichotomous-choice test as a method for quantifying male mate choice in fishes. This particular test is commonly used in mate-choice studies, but it has received some criticisms (Houde 1997; Wagner 1998; Gabor 1999). For this reason, it was important to validate my protocol before performing my experiments testing male mate choice in relation to sperm competition and female fecundity in the guppy. In my study, male mating preference measured in the dichotomous-choice test predicted mating preference when males were allowed to swim freely with the females. Based on these results, I am confident that the findings reported in subsequent chapters reflect male mating behaviours that would occur in nature. My results are also useful for any future studies aiming to test male guppy preferences for female qualities that can be assessed using visual cues alone.

The results reported in Chapters 3 and 4 further contribute to our understanding of the types of quality-related cues males use to discriminate between females as potential mates and how they assess these cues. For example, males used visual cues (female body size) to assess female fecundity and selected larger, more fecund females when given a choice between two females that differed considerably in size. By choosing to mate with a more fecund female, a male can increase his reproductive success by maximizing the number of eggs he can potentially fertilize (Andersson 1994; Bonduriansky 2001). My results corroborate previous studies on guppies (Dosen \& Montgomerie 2004a; Herdman et al. 2004) and further contribute to the body of empirical evidence demonstrating that males prefer to mate with larger, more fecund females in fishes (e.g. Côté \& Hunte 1989; Nuttall \& Keenleyside 1993; Ptacek \& Travis 1997; Kraak \& Bakker 1998). 
In addition to female fecundity, males also discriminated between females based on their immediate SCR. As discussed in Chapter 1, because sperm competition can generate variation in female quality, a male can potentially increase his reproductive success by choosing a female associated with a lower SCR (Simmons 2001). Males can potentially use a number of cues to assess their immediate SCR, depending on the species (Parker et al. 1997; Simmons 2001). A previous study on guppies found that males used chemical cues to distinguish between virgin and recently-mated females (Guevara-Fiore et al. 2009). Social cues can also provide valuable information when it is difficult to distinguish between potential mates (Dall et al. 2005). Therefore, I tested whether male guppies also use the socio-sexual cues that are available in nature to assess immediate SCR. Similar to Guevara-Fiore et al. (2009), I found that males identified and selected against females they perceived as being associated with a higher SCR. Therefore, my results demonstrate that male guppies also use social information to assess SCR, which corroborates previous studies that found males interacting with or in close proximity to a female can influence a male's mating behaviour (Schwagmeyer \& Parker 1990; White \& Galef 1999; Smith et al. 2003; Dosen \& Montgomerie 2004b; Wong \& McCarthy 2009). It would be interesting to further investigate how and when male guppies use sociosexual cues and chemical cues in making mate-choice decisions, and whether one type of cue is considered more reliable than the other.

When males were given information on both a female's fecundity and immediate SCR, fecundity appeared to outweigh social information predicting SCR. Most males reversed their preference after viewing their initially-preferred female with another male when the paired females were similar in size; however, if the initially-preferred female 
was relatively larger than the paired female, males consistently preferred the larger female irrespective of their perceived SCR. The most likely explanation for this behaviour is that even though the larger female had a higher perceived SCR, the ratio of fertilizable eggs to sperm may have still been higher in the larger female than in the smaller one (c.f. Reinhold et al. 2002). If this were the case, then a male who chose to mate with the larger female would still fertilize more eggs and therefore have a higher reproductive success. However, my results were only significant when I analyzed the data categorically (mate-choice reversals); therefore, more research is needed to corroborate my findings.

More research is also needed to fully understand how increasing levels of immediate SCI affect male mate choice in the guppy. Although male mating behaviour was sensitive to an elevated SCR, it was not affected by social information predicting immediate SCI. It is possible that I did not use a sufficiently large number of rival males to simulate an increase in SCI, in light of the previous study of Dosen \& Montgomerie (2004b) who used four rival males to simulate SCI in a population of lab-reared Venezuelan guppies. However, since I observed a maximum of only two male guppies simultaneously pursuing a female in nature, increasing the number of males above two would not have been ecologically relevant for my study population (Quaré River). Instead, it appears that socially-acquired information that predicts sperm competition only conveys discrete information (i.e. whether or not there is an elevated level of SCR associated with a particular female) as opposed to graded information (the level of SCI) to male guppies. This does not, however, rule out the possibility that male guppies are sensitive to immediate SCI, because they may use other cues to assess SCI or other 
tactics when responding to an increase in the immediate SCI. Future studies should thus focus on potential cues males could use to assess SCI, such as chemical cues, and alternative male responses, such as cryptic male mate choice (described below). The latter behaviour has been reported for other fishes (Pilastro et al. 2002; Smith et al. 2003), but not yet in the guppy.

Research into cryptic male mate choice could provide further insights into the evolution of male mating behaviour. In the current study, I investigated pre-copulatory mate choice, which is whether a male chooses to mate with or reject a female. Cryptic male mate choice, on the other hand, involves a male allocating more or less sperm to a particular female (Parker 1970). This is different from males facultatively adjusting the size of their ejaculate in response to variations in the ambient operational sex ratio; in this particular case, males simply increase or decrease the number of sperm allocated to all females rather than to specific individual females (Bonduriansky 2001). There are a number of questions regarding cryptic male mate choice that could be investigated in future studies using the guppy as a model system. For example, it is unknown whether male guppies allocate more sperm to larger females. Males of other species have been found to increase the number of sperm they invest in a mating depending on the female's quality (e.g. Gage \& Barnard 1996; Wedell \& Cook 1999). There may also be selection for this behaviour in guppies because larger females have more eggs (Reznick \& Endler 1982; Reznick 1983) and are also associated with a higher SCR (Kelly et al. 1999; Becher \& Magurran 2004; Herdman et al. 2004; Neff et al. 2008). Male guppies may also be able to adjust their ejaculate size in order to circumvent the costs associated with being choosy. Males potentially benefit from being choosy, but choosiness can still be 
$\therefore \quad$ for a variety of reasons, including the risk of rejecting a female of higher quality ia.1 what a male may encounter later (Bonduriansky 2001). It would be interesting to tesi whether males that do not reject females associated with an elevated SCR adaptively adjust their ejaculate sizes instead.

Another potentially fruitful area of research is whether or not a male's response to SCR also depends on the relative attractiveness of rival males. Male guppies vary widely in their ability to out compete other males in sperm competition (Evans \& Magurran 2001; Pitcher et al. 2002; Evans \& Rutstein 2008), and there are a number of cues that a male could use to assess a rival male's competitive ability. For example, body orange coloration in male guppies is positively correlated with sperm number, motility and length (Pitcher et al. 2007), and body size (Pitcher \& Evans 2001; Evans et al. 2002) and courtship behaviour (Matthews et al. 1997; Evans et al. 2002) are both positively correlated with sperm numbers. In my study, the average amount of orange coloration on the bodies of focal males and rival males did not differ significantly. In addition to the quantity and quality of a rival male's sperm, female preference may also determine which male gains the most fertilizations. Guppies experience a last-male precedence in sperm use, but the last male to mate with a female will fertilize a relatively smaller proportion of her eggs if the previous male is more attractive (Pitcher et al. 2002). It is possible that male guppies estimate their own attractiveness based on past experiences with females, as females are more receptive to attractive males (Houde 1997). Therefore, males may be able to assess the relative attractiveness of a rival male he views copulating with a female. Alternatively, a male may simply assess the absolute attractiveness of the other male, irrespective of his own phenotype. In either case, it would be interesting to titrate 
the relative and absolute attractiveness of the rival male to determine whether this affects the focal male's behaviour.

In conclusion, my study contributes further to our general understanding of the factors influencing mate-choice behaviour in males. More specifically, I validated a commonly-used experimental protocol for quantifying mating preferences, corroborated previous studies that found males discriminate between females based on visual cues predicting fecundity and socio-sexual cues predicting SCR, and lastly demonstrated that males simultaneously assess female fecundity and immediate SCR in making matechoice decisions. My findings also generated several questions that could form fruitful areas of future research. 


\section{REFERENCES}

Ancona, S., Drummond, H. \& ZaldÌvar-Rae, J. 2010. Male whiptail lizards adjust energetically costly mate guarding to male-male competition and female reproductive value. Anim. Behav., 79, 75-82.

Andersson, M. 1994. Sexual Selection. Princeton University Press, Princeton.

Becher, S. A. \& Magurran, A. E. 2004. Multiple mating and reproductive skew in Trinidadian guppies. Proc. R. Soc. Lond. B, 271, 1009-1014.

Birkhead, T. 2000. Promiscuity: An Evolutionary History of Sperm Competition and Sexual Conflict. Faber \& Faber Ltd., London.

Birkhead, T. R. \& Møller, A. P. 1998. Sperm Competition and Sexual Selection. Academic Press, New York.

Bisazza, A., Marconato, A. \& Marin, G. 1989. Male mate preferences in the Mosquitofish Gambusia holbrooki. Ethology, 83, 335-343.

Bischoff, R. J., Gould, J. L. \& Rubenstein, D. I. 1985. Tail size and female choice in the guppy (Poecilia reticulata). Behav. Ecol. and Sociobiol., 17, 253-255.

Blumstein, D. T. \& Daniel, J. C. 2007. Quantifying Behaviour the JWatcher way. Sinauer Associates, Sunderiand, MA.

Bonduriansky, R. 2001. The evolution of male mate choice in insects: a synthesis of ideas and evidence. Biol. Rev., 76, 305-339. 
Candolin, U. 2003. The use of multiple cues in mate choice. Biological Reviews, 78, 575595.

Clayton, N. S. 1990. Assortative mating in zebra finch subspecies. Taeniopygia guttata guttata and T. g. castanotis. Philos. Trans. R. Soc. Lond. B, 330, 351-370.

Clutton-Brock, T. 2007. Sexual selection in males and females. Science, 318, 1882-1885.

Constantz, G. D. 1984. Sperm competition in poeciliid fishes. In: Sperm Competition and the Evolution of Animal Mating Systems (Ed. by Smith, R. L.), pp. 465-485. Academic Press, New York.

Côté, I. M. \& Hunte, W. 1989. Male and female mate choice in the redlip blenny: why bigger is better. Anim. Behav., 38, 78-88.

Cummings, M. \& Mollaghan, D. 2006. Repeatability and consistency of female preference behaviours in a northern swordtail, Xiphophorus nigrensis. Anim. Behav., 72, 217-224.

Dall, S. R. X., Giraldeau, L.-A., Olsson, O., McNamara, J. M. \& Stephens, D. W. 2005. Information and its use by animals in evolutionary ecology. Trends Ecol. Evol., $20,187-193$.

Danchin, E., Giraldeau, L.-A., Valone, T. J. \& Wagner, R. H. 2004. Public information: from nosy neighbors to cultural evolution. Science, 305, 487-491.

Deaton, R. 2008. Factors influencing male mating behaviour in Gambusia affinis (Baird \& Girard) with a coercive mating system. J. Fish Biol., 72, 1607-1622. 
Dewsbury, D. A. 1982. Ejaculate cost and male choice. Am. Nat., 119, 601-610.

Dosen, L. D. \& Montgomerie, R. 2004a. Female size influences mate preferences of male guppies. Ethology, 110, 245-255.

Dosen, L. D. \& Montgomerie, R. 2004b. Mate preferences by male guppies (Poecilia reticulata) in relation to the risk of sperm competition. Behav. Ecol. Sociobiol., $55,266-271$

Dugatkin, L. A. \& Godin, J.-G. J. 1992. Reversal of female mate choice by copying in the guppy (Poecilia reticulata). Proc. $R$. Soc. Lond. B, 249, 179-184.

Engqvist, L. \& Reinhold, K. 2005. Pitfalls in experiments testing the predictions from sperm competition. J. Evol. Biol., 18, 116-123.

Engqvist, L. \& Sauer, K. P. 2001. Strategic male mating effort and cryptic male choice in a scorpionfly. Proc. R. Soc. Lond. B, 268, 729-735.

Erdfelder, E., Faul, F. \& Buchner, A. 1996. GPOWER: A general power analysis program. Behav. Res. Meth. Ins. C., 28, 1-11.

Evans, J. P. 2009. No evidence for sperm priming responses under varying sperm competition risk or intensity in guppies. Naturwissenschaften, 96, 771-779.

Evans, J. P. \& Magurran, A. E. 2001. Patterns of sperm precedence and predictors of paternity in the Trinidadian guppy. Proc. R. Soc. Lond. B, 268, 719-724. 
Evans, J. P., Pilastro, A. \& Ramnarine, I. W. 2003a. Sperm transfer through forced matings and it evolutionary implications in natural guppy (Poecilia reticulata) populations. Biol. J. Linn. Soc., 78, 605-612.

Evans, J. P., Pitcher, T. \& Magurran, A. E. 2002. The ontogeny of courtship, colour and sperm production in male guppies. J. Fish Biol., 60, 495-498.

Evans, J. P. \& Rutstein, A. N. 2008. Postcopulatory sexual selection favours intrinsically good sperm competitors. Behav. Ecol. Sociobiol., 62, 1167-1173.

Evans, J. P., Zane, L., Francescato, S. \& Pilastro, A. 2003b. Directional postcopulatory sexual selection revealed by artificial insemination. Nature, 421, 360-363.

Fuller, R. C. 1998. Sperm competition affects male behaviour and sperm output in the rainbow darter. Proc. R. Soc. Lond. B, 265, 2365-2371.

Gabor, C. 1999. Association patterns of sailfin mollies (Poecilia latipinna): alternative hypotheses. Behav. Ecol. Sociobiol., 46, 333-340.

Gage, A. R. \& Barnard, C. J. 1996. Male crickets increase sperm number in relation to competition and female size. Behav. Ecol. Sociobiol., 38, 349-353.

Gage, M. J. G. 1998. Influences of sex, size, and symmetry on ejaculate expenditure in a moth. Behav. Ecol., 9, 592-597.

Galvani, A. \& Johnstone, R. 1998. Sperm allocation in an uncertain world. Behav. Ecol. Sociobiol., 44, 161-168. 
Godin, J.-G. J. 1995. Predation risk and alternative mating tactics in male Trinidadian guppies (Poecilia reticulata). Oecologia, 103, 224-229.

Guevara-Fiore, P., Skinner, A. \& Watt, P. J. 2009. Do male guppies distinguish virgin females from recently mated ones? Anim. Behav., 77, 425-431.

Guevara-Fiore, P., Stapley, J., Krause, J., Ramnarine, I. W. \& Watt, P. J. 2010. Male mate-searching strategies and female cues: how do male guppies find receptive females? Anim. Behav., 79, 1191-1197.

Herdman, E. J. E., Kelly, C. D. \& Godin, J.-G. J. 2004. Male mate choice in the guppy (Poecilia reticulata): do males prefer larger females as mates? Ethology, 110, 97 111.

Houde, A. E. 1997. Sex, Color, and Mate Choice in Guppies. Princeton University Press, Princeton.

Hoysak, D. J. \& Godin, J.-G. J. 2007. Repeatability of male mate choice in the mosquitofish, Gambusia holbrooki. Ethology, 113, 1007-1018.

Hughes, K. A., Du, L., Rodd, F. H. \& Reznick, D. N. 1999. Familiarity leads to female mate preference for novel males in the guppy, Poecilia reticulata. Anim. Behav., $58,907-916$

Kelley, J. L., Graves, J. A. \& Magurran, A. E. 1999. Familiarity breeds contempt in guppies. Nature, 401, 661-662. 
Kelly, C. D., Godin, J.-G. J. \& Wright, J. M. 1999. Geographical variation in multiple paternity within natural populations of the guppy (Poecilia reticulata). Proc. $R$. Soc. Lond. B, 266, 2403-2408.

Kodric-Brown, A. 1989. Dietary carotenoids and male mating success in the guppy: an environmental component to female choice. Behav. Ecol. Sociobiol., 25, 393-401.

Kraak, S. B. M. \& Bakker, T. C. M. 1998. Mutual mate choice in sticklebacks: attractive males choose big females, which lay big eggs. Anim. Behav., 56, 859-866.

Lehtonen, T. K. \& Lindström, K. 2008. Repeatability of mating preferences in the sand goby. Anim. Behav., 75, 55-61.

Locatello, L., Rasotto, M. B., Evans, J. P. \& Pilastro, A. 2006. Colourful male guppies produce faster and more viable sperm. J. Evol. Biol., 19, 1595-1602.

Magurran, A. E. 2005. Ecology and Evolution: The Trinidadian Guppy. Oxford University Press, Oxford.

Magurran, A. E. \& Seghers, B. H. 1994. Sexual conflict as a consequence of ecology: evidence from guppy, Poecilia reticulata, populations in Trinidad. Proc. R. Soc. Lond. B, 255, 31-36.

Martin, P. \& Bateson, P. 1986. Measuring Behaviour: An Introductory Guide. Cambridge University Press, Cambridge. 
Matthews, I. M., Evans, J. P. \& Magurran, A. E. 1997. Male display rate reveals ejaculate characteristics in the Trinidadian guppy Poecilia reticulata. Proc. R. Soc. Lond. $B, 264,695-700$.

Matthews, I. M. \& Magurran, A. E. 2000. Evidence for sperm transfer during sneaky mating in wild Trinidadian guppies. J. Fish Biol., 56, 1381-1386.

McLennan, D. A. 1995. Male mate choice based upon female nuptial coloration in the brook stickleback, Culaea inconstans (Kirtland). Anim. Behav., 50, 213-221.

Muller, M. N., Thompson, M. E. \& Wrangham, R. W. 2006. Male chimpanzees prefer mating with old females. Curr. Biol., 16, 2234-2238.

Nakatsuru, K. \& Kramer, D. L. 1982. Is sperm cheap? Limited male fertility and female choice in the Lemon Tetra (Pisces, Characidae). Science, 216, 753-755.

Neff, B. D., Pitcher, T. \& Ramnarine, I. W. 2008. Inter-population variation in multiple paternity and reproductive skew in the guppy. Mol. Ecol., 17, 2975-2984.

Nuttall, D. B. \& Keenleyside, M. H. A. 1993. Mate choice by the male convict cichlid (Cichlasoma nigrofasciatum; Pisces, Cichlidae). Ethology, 95, 247-256.

Ojanguren, A. F. \& Magurran, A. E. 2004. Uncoupling the links between male mating tactics and female attractiveness. Proc. R. Soc. Lond. B, 271, S427-S429.

Parker, G. A. 1970. Sperm competition and its evolutionary consequences in the insects. Biol. Rev., 45, 525-567. 
Parker, G. A., Ball, M. A., Stockley, P. \& Gage, M. J. G. 1996. Sperm competition games: individual assessment of sperm competition intensity by group spawners. Proc. R. Soc. Lond. B, 263, 1291-1297.

Parker, G. A., Ball, M. A., Stockley, P. \& Gage, M. J. G. 1997. Sperm competition games: a prospective analysis of risk assessment. Proc. R. Soc. Lond. B, 264, 1793-1802.

Parker, G. A., Simmons, L. W., Stockley, P., McChristie, D. M. \& Charnov, E. L. 1999. Optimal copula duration in yellow dung flies: effects of female size and egg content. Anim. Behav., 57, 795-805.

Pilastro, A. \& Bisazza, A. 1999. Insemination efficiency of two alternative male mating tactics in the guppy (Poecilia reticulata). Proc. R. Soc. Lond. B, 266, 1887-1891.

Pilastro, A., Scaggiante, M. \& Rasotto, M. B. 2002. Individual adjustment of sperm expenditure accords with sperm competition theory. Proc. Natl. Acad. Sci. USA, 99, 9913-9915.

Pitcher, T. E. \& Evans, J. P. 2001. Male phenotype and sperm number in the guppy (Poecilia reticulata). Can. J. Zool., 79, 1891-1896.

Pitcher, T. E., Neff, B. D., Rodd, F. H. \& Rowe, L. 2002. Multiple mating and sequential mate choice in guppies: females trade-up. Proc. R. Soc. Lond. B, 270, 1623-1629.

Pitcher, T. E., Rodd, F. H. \& Rowe, L. 2007. Sexual colouration and sperm traits in guppies. J. Fish Biol., 70, 165-177. 
Plath, M., Blum, D., Schlupp, I. \& Tiedemann, R. 2008. Audience effect alters mating preferences in a livebearing fish, the Atlantic molly, Poecilia mexicana. Anim. Behav., 75, 21-29.

Ptacek, M. B. \& Travis, J. 1997. Mate Choice in the Sailfin Molly, Poecilia latipinna. Evolution, 51, 1217-1231.

Reinhold, K., Kurtz, J. \& Engqvist, L. 2002. Cryptic male choice: sperm allocation strategies when female quality varies. J. Evol. Biol., 15, 201-209.

Reznick, D. 1983. The structure of guppy life histories: the tradeoff between growth and reproduction. Ecology, 64, 862-873.

Reznick, D. \& Endler, J. A. 1982. The impact of predation on life history evolution in Trinidadian guppies (Poecilia reticulata). Evolution, 36, 160-177.

Ryan, M. J., Hews, D. K. \& Wagner, W. E. J. 1990. Sexual selection on alleles that determine body size in the swordtail Xiphoporus nigrensis. Behav. Ecol. Sociobiol., 26, 231-237.

Schlupp, I. \& Ryan, M. J. 1997. Male sailfin mollies (Poecilia latipinna) copy the mate choice of other males. Behav. Ecol., 8, 104-107.

Schwagmeyer, P. L. \& Parker, G. A. 1990. Male mate choice as predicted by sperm competition in thirteen-lined ground squirrels. Nature, 348, 62-64.

Shapiro, D. Y., Marconato, A. \& Yoshikawa, T. 1994. Sperm economy in a coral reef fish, Thalassoma bifasciatum. Ecology, 75, 1334-1344. 
Simmons, L. W. 2001. Sperm Competition and its Evolutionary Consequences in the Insects. Princeton University Press, Princeton.

Smith, C., Reichard, M. \& Jurajda, P. 2003. Assessment of sperm competition by European bitterling, Rhodeus sericeus. Behav. Ecol. Sociobiol., 53, 206-213.

Wagner, W. E. J. 1998. Measuring female mating preferences. Anim. Behav., 55, 10291042.

Walling, C., Royle, N., Lindström, J. \& Metcalfe, N. 2010. Do female association preferences predict the likelihood of reproduction? Behav. Ecol. Sociobiol., 64, $541-548$.

Wedell, N. \& Cook, P. A. 1999. Butterflies tailor their ejaculate in response to sperm competition risk and intensity. Proc. R. Soc. Lond. B, 266, 1033-1039.

Wedell, N., Gage, M. J. G. \& Parker, G. A. 2002. Sperm competition, male prudence and sperm-limited females. Trends Ecol. Evol., 17, 313-320.

White, D. J. \& Galef, B. G. 1999. Social effects on mate choices of male Japanese quail, Coturnix japonica. Anim. Behav., 57, 1005-1012.

Witte, K. 2006. Time spent with a male is a good indicator of mate preference in female zebra finches. Ethol. Ecol. Evol., 18, 195-204.

Wong, B. B. M. \& Jennions, M. D. 2003. Costs influence male mate choice in a freshwater fish. Proc. R. Soc. Lond. B, 270, S36-S38. 
Wong, B. B. M. \& McCarthy, M. 2009. Prudent male mate choice under perceived sperm competition risk in the eastern mosquito fish. Behav. Ecol., 20, 278-282.

Zajitschek, S. R. K., Evans, J. P. \& Brooks, R. 2006. Independent effects of familiarity and mating preferences for ornamental traits on mating decisions in guppies. Behav. Ecol., 17, 911-916. 